\title{
EL MONOPOLIO DE LAS IDEAS: CONTRA LA PROPIEDAD INTELECTUAL*
}

\author{
ALBERT ESPLUGAS**
}

Resumen: En este trabajo se presenta una crítica a la propiedad intelectual desde una perspectiva ética y económica. Tras caracterizar las patentes y los copyrights como monopolios sobre ideas, se arguye que la propiedad intelectual viola el derecho de propiedad privada en su sentido tradicional y crea una escasez artificial en lugar de fundarse sobre la escasez. Se cuestiona, asimismo, que la propiedad intelectual suponga un incentivo a la creación, estudiando los distintos costes de una regulación de este tipo. Por último se mencionan varias alternativas de mercado para hacer frente a los problemas de free-riding.

Palabras clave: propiedad intelectual, patentes, copyrights, propiedad privada, escasez, bien público, incentivos a la innovación, mercado.

Abstract: This paper presents a critique of intellectual property from an ethical and economical point of view. Once patents and copyrights are characterized as a monopolies of ideas, it is argued that intellectual property violates private property rights in its original meaning and it is not based in real scarcity but creates artificial scarcity instead. In addition, the paper challenges intellectual property as an incentive to innovation and studies the several costs of this kind of regulation. Eventually, different market alternatives to tackle the free-riding problem are explored.

Key words: intelectual property, patents, copyrights, private property, scarcity, public good, innovation incentives, market economy.

Clasificación JEL: O310, O320, O340, H410.

(*) Agradezco a Francisco Capella sus comentarios a un primer borrador de este ensayo y a Gabriel Calzada el que me brindara la oportunidad de presentar las ideas contenidas en este trabajo en un coloquio en el Instituto Juan de Mariana. Asimismo quiero agradecer a un evaluador anónimo diversos comentarios y sugerencias que contribuyeron a mejorar el texto original. Cualquier error contenido en éste sólo es atribuible a su autor.

${ }^{* *}$ ) Universidad Pompeu Fabra (Barcelona). 


\section{INTRODUCCIÓN}

La propiedad intelectual, en su sentido anglosajón, es un término amplio que comprende distintas categorías de derechos legales que se derivan de algún tipo de creatividad intelectual. Más sintéticamente y en otras palabras, la propiedad intelectual es un derecho sobre objetos ideales, intangibles, inmateriales; es un derecho de propiedad sobre ideas ${ }^{1}$. La propiedad intelectual nos remite, pues, a conceptos tales como las patentes, los copyrights o derechos de autor, las marcas y los secretos comerciales ${ }^{2}$. De estos dos últimos nos ocuparemos al final por separado, pues creemos que reúnen ciertas características especiales y que merecen un tratamiento específico, de modo que a lo largo de este ensayo el término «propiedad intelectual» aludirá con carácter general a las patentes y a los copyrights, conceptos íntimamente relacionados que serán examinados de forma conjunta ${ }^{3}$.

En el presente trabajo desarrollaremos una crítica de la propiedad intelectual impugnando tanto sus fundamentos éticofilosóficos como su justificación utilitarista, de índole económica.

En su vertiente ética la crítica tendrá un enfoque consonante con el iusnaturalismo, ley natural o derechos naturales privativos del liberalismo clásico o libertarismo ${ }^{4}$. El centro de nuestra

1 Kinsella (2001).

2 Íbid.

3 Cabe puntualizar que «propiedad intelectual» se empleará a lo largo de este escrito en su sentido anglosajón, que como hemos visto engloba distintos conceptos relacionados con la propiedad de las ideas. En España «propiedad intelectual» equivale a «derechos de autor» y se maneja el término "propiedad industrial» para referirse a las patentes y a otros certificados. Aquí nos interesa la propiedad sobre ideas, no únicamente la propiedad sobre una clase (artificialmente aislada) de ideas, motivo por el cual se empleará el término en su sentido más omnicomprensivo. Véase el Real Decreto Legislativo 1/1996, de 12 de abril, por el que se aprueba el Texto Refundido de la Ley de Propiedad Intelectual y la Ley 11/1986, de 20 de marzo, de Patentes de Invención y Modelos de utilidad.

4 Una excelente introducción a la ética liberal puede encontrarse en Rothbard (1973), segundo capítulo. Para un desarrollo exhaustivo de la filosofía política liberal véase Rothbard (1982). 
atención será, por tanto, los derechos individuales, la libertad individual, la propiedad como núcleo de una ética acorde con la naturaleza actuante del hombre. Es significativo destacar que acaso las justificaciones éticas más sólidas del concepto de propiedad intelectual provengan también de este campo (o se fundamenten en sus mismos principios), con lo cual el combate dialéctico tendrá lugar con idénticas o similares armas y los contendientes compartirán la causa de una sociedad libre ${ }^{5}$.

En su vertiente económica la crítica cuestionará los alegatos utilitaristas en defensa de la propiedad intelectual, poniendo en duda que los monopolios legales sobre las ideas constituyan un incentivo para la creación y que sin esta suerte de auxilio el progreso se resentiría. Veremos como los beneficios derivados de la propiedad intelectual quizás no son tan voluminosos como sus abogados arguyen, y como por otro lado los costes no tangibles (aquello que «se deja de ganar») resultan considerables, hasta el punto de que quizás eclipsen los presuntos beneficios tangibles de estas políticas.

${ }^{5}$ Como apunta Tom Palmer, esto no es extraño, pues son los valedores del libre mercado los más comprometidos con la teoría de los derechos de propiedad y su aplicación. Palmer (1990). Entre los teóricos liberales favorables a la propiedad intelectual cabe destacar a Lysander Spooner, Herbert Spencer, Ayn Rand, Neil Schulman, Andrew Galambos, George Reisman, Milton Friedman, David Kelley o Murray Frank. David Friedman parece justificar también la propiedad intelectual desde postulados utilitaristas. Entre los liberales contrarios a las patentes y a los copyrights destacan Benjamin Tucker, William Legget, Wendy McElroy, Tom Palmer, Roderick Long, Stephan Kinsella, Bowdewijn Bouckaert, Julio Cole o Jesse Walker. Friedrich Hayek pareció mostrarse cuando menos escéptico con respecto a la propiedad intelectual, lo mismo que Thomas Jefferson. El caso de Murray Rothbard es ambivalente, pues aunque se opuso a las patentes sí defendió los derechos reservados del copyright. También Herny George se opuso a las patentes y justificó el copyright. Véase Kinsella (2001) y Cole (2001). 


\section{PATENTES Y COPYRIGHTS}

Delimitemos, en primer lugar, el concepto de propiedad intelectual: la propiedad intelectual es un derecho sobre objetos ideales, inmateriales, un derecho de propiedad sobre ideas. En lo atinente a las patentes y a los copyrights Julio Cole señala: «Las patentes y los copyrights son formas de 'propiedad' inmaterial que garantizan a sus poseedores un control exclusivo sobre la producción y venta de un bien específico - un trabajo literario en el caso de los copyrights, una invención o proceso productivo en el caso de las patentes» ${ }^{6}$. Cole introduce así la distinción primaria entre patentes y copyrights o derechos de autor, que a continuación concretamos:

Las patentes representan derechos de propiedad sobre invenciones; sobre artefactos, dispositivos o procesos que desarrollen una función «útil» 7 . No son patentables las leyes de la naturaleza, los fenómenos naturales o las ideas abstractas, sino la plasmación de ideas en aplicaciones prácticas. La patente confiere al creador-inventor un derecho exclusivo sobre la explotación, el uso y la venta de la invención ${ }^{8}$.

Los copyrights o derechos de autor son derechos de propiedad asignados a los autores de trabajos originales artísticos, literarios o científicos: libros, artículos, películas, composiciones musicales, programas de ordenador etc. Lo mismo que la

6 Cole (2001).

7 En el ordenamiento jurídico español «[s]on patentables las invenciones nuevas, que impliquen actividad inventiva y sean susceptibles de aplicación industrial, aun cuando tengan por objeto un producto que esté compuesto o que contenga materia biológica, o un procedimiento mediante el cual se produzca, transforme o utilice materia biológica.» Ley de Patentes de Invención y Modelos de Utilidad 11/1986 de 20 de marzo, Artículo 4.1.

8 Kinsella (2001). En rigor la patente no garantiza un derecho a usar la invención, sino un derecho a impedir que terceros lo hagan. El inventor de un carburador mejorado puede patentarlo e impedir que otros apliquen las mejoras que él ha concebido, pero no puede hacer uso del carburador mejorado a menos que el titular de la patente del carburador original le permita utilizar éste. 
patente, el copyright confiere al autor-creador un derecho exclusivo a reproducir el trabajo, explotarlo comercialmente o presentarlo al público9 .

En síntesis, la propiedad intelectual supone un derecho de propiedad sobre ideas, plasmadas en una aplicación práctica (caso de las patentes) o expresadas (caso de los copyrights) ${ }^{10}$.

\section{PROPIEDAD PRIVADA SOBRE BIENES TANGIBLES}

Siguiendo al filósofo del siglo XVII John Locke, uno de los primeros autores en sistematizar una ética liberal de los derechos naturales, es preciso desarrollar ahora el concepto de propiedad tradicional. El pasaje trascrito a continuación corresponde a su Second Treatise of Government y hace referencia al derecho de propiedad clásico, al acto de apropiación original por el cual los bienes «desocupados» que la naturaleza ofrece son apartados de su seno por el hombre y convertidos en propiedad privada:

... cada uno de los hombres es propietario de su propia persona. Nadie sino él tiene derecho sobre ella. Podemos decir que el trabajo de su cuerpo y las obras de sus manos son estrictamente suyos. Cuando aparta una cosa del estado que la naturaleza le ha proporcionado y depositado en ella y mezcla con ella su trabajo, le añade algo que es suyo, convirtiéndola así en su propiedad. Ahora existe a su lado, separada del estado común

\footnotetext{
9 Kinsella (2001). La Ley de la Propiedad Intelectual española dice: «Artículo 1. La propiedad intelectual de una obra literaria, artística o científica corresponde al autor por el solo hecho de su creación. Artículo 2. La propiedad intelectual está integrada por derechos de carácter personal y patrimonial, que atribuyen al autor la plena disposición y el derecho exclusivo a la explotación de la obra, sin más limitaciones que las establecidas en la Ley.» Texto Refundido de la Ley de Propiedad Intelectual, Real Decreto Legislativo 1/1996, de 12 de abril.

10 Kinsella (2001).
} 
de la naturaleza puesta en ella. Con su trabajo le ha añadido algo que la excluye del derecho común de las demás personas. Dado que este trabajo es propiedad indiscutible del trabajador, nadie puede tener derecho sobre aquello que ha añadido... ${ }^{11}$

Luego el individuo se apropia de un bien en el estado de la naturaleza cuando lo descubre e imprime su sello particular en él, cuando mediante su acción lo separa de la naturaleza, cuando mezcla su trabajo con el objeto, cuando lo usa u ocupa, en suma, por primera vez. El individuo es propietario de sí mismo y, por extensión, deviene también propietario de aquello que, no siendo de nadie previamente, recibe el influjo de su personal acción ${ }^{12}$. Entonces un vínculo existe entre este bien y el individuo que le ha dado utilidad que no existe entre dicho bien y nadie más. Tal es el fundamento objetivo de la propiedad privada, entendida como el derecho al control exclusivo de un determinado bien, cosa, objeto. El individuo ostenta así el derecho a decidir con respecto a su propiedad, a darle el uso que estime oportuno de acuerdo con sus fines particulares, sin ninguna interferencia por parte de terceros y con la única limitación de no invadir-agredir la propiedad ajena. En la medida en que no se respete este control de la persona sobre sus posesiones legítimamente adquiridas se estará violando su derecho de propiedad.

11 John Locke, «Two Treatises of Government», citado en Rothbard (1982, p. 49).

12 «Cada individuo se percata de su propia condición y forma, e incluso de la existencia de sus miembros y de su cuerpo, viéndolos y sintiéndolos. Esto constituye su noción de la identidad personal, tanto para él como para los demás; y es imposible concebir - es de hecho una contradicción afirmar- que los miembros y el cuerpo de un hombre no le pertenecen, pues las palabras "le", "a sí mismo" y "su cuerpo" remiten a la misma cosa material. En la medida en que aprehendemos la existencia de nuestros propios cuerpos percibiéndolos, y en la medida en que percibimos los cuerpos de los demás, tenemos precisamente razones análogas para creer en la individualidad o identidad de otras personas, así como para creer en nuestra propia identidad. Las ideas expresadas por las palabras "mío" y "tuyo", aplicadas al producto del trabajo, son entonces simplemente una prolongación de las ideas de identidad personal e individualidad». T. Hodskin, «The Natural and Artificial Right of Property Contrasted», citado en Palmer (1990). 
¿En qué sentido la propiedad intelectual enlaza con el concepto de propiedad privada tradicional expuesto? Para los defensores iusnaturalistas ${ }^{13}$ de la propiedad intelectual, tanto ésta como la propiedad tradicional son el producto de la labor y el pensamiento del individuo. En la línea de Locke, se arguye que «uno tiene el derecho a los frutos de su trabajo. De acuerdo con esta visión, del mismo modo que uno tiene derecho a los cereales que cultiva, también tiene uno derecho a las ideas que genera y al arte que produce» ${ }^{14}$. En palabras del pensador decimonónico Lysander Spooner, ardiente defensor de la propiedad intelectual, «aquél que descubre, o primero toma posesión, de una idea, deviene su lícito y legítimo propietario; de acuerdo con el mismo principio que aquél que primero toma posesión de cualquier producto material de la naturaleza se convierte en su legítimo propietario (...) Pero si se trata de ideas que no preexisten en la naturaleza (...) sino que son creadas por su labor -la labor de su mente-entonces el derecho de propiedad corresponde a aquel cuya labor las ha creado» ${ }^{15}$. En efecto, este razonamiento parece impecablemente lockeano. La semejanza, no obstante, es sólo aparente.

\section{PERSPECTIVA ÉTICA}

Al concepto de propiedad intelectual cabe oponer varios argumentos de tipo ético esencialmente que atacan de raíz su justificación, poniendo de manifiesto las contradicciones y las inconsistencias de dicho concepto. No se trata de apelar a ninguna suerte de «derecho social» a la difusión de las ideas o a

13 Los iusnaturalista defienden la existencia de unos derechos naturales. En contraposición, los utilitaristas no apelan a unos derechos naturales, sino a la maximización del bienestar social o de la utilidad. Volveremos sobre este punto más adelante. Hay proponentes iusnaturalistas y utilitaristas liberales en ambos bandos de esta discusión.

14 Kinsella (2001).

15 Spooner (1855). 
un supuesto carácter colectivo de las mismas. En este sentido estamos plenamente de acuerdo con Spooner cuando señala que «las ideas emanan de la mente del individuo. Abandonan su mente sólo en obediencia a su voluntad. Mueren con él si así lo elige» 16 .

\section{Propiedad intelectual o derechos sobre la propiedad ajena}

Locke sostiene que el individuo deviene propietario de aquella materia tangible en la que ha impreso su sello distintivo, en la que ha plasmado su creatividad, no de la idea en sí misma que como tal puede concretarse en otros objetos tangibles. Como indica Tom Bell de un modo gráfico, "[Locke] habla de la propiedad de los átomos, no de la propiedad de los bits» ${ }^{17}$.

La propiedad intelectual es un derecho sobre objetos ideales, sobre ideas. Esto significa que se confiere al titular de la propiedad intelectual un derecho sobre todas las plasmaciones físicas de la idea protegida, es decir, el creador-inventor retiene un derecho de control sobre la propiedad ajena en lo tocante a la plasmación de la idea protegida. Nadie puede plasmar esta idea en su propiedad tangible sin el consentimiento del creador-inventor, luego el creador-inventor detenta un derecho de control parcial sobre la propiedad tangible de terceros, ya que ostenta la potestad de decidir, con respecto a la plasmación de la idea, sobre el uso de esta propiedad tangible.

El autor de un libro, valiéndose del copyright, no sólo posee un derecho de propiedad sobre el ejemplar que ha escrito (lo cual nadie niega), sino que detenta un derecho de propiedad parcial sobre toda la tinta y las hojas en blanco propiedad de terceros, ya que puede impedir que estos, con su tinta y con sus hojas, reproduzcan las ideas expresadas en la obra original.

\footnotetext{
16 Palmer (1990).

17 Bell (2002).
} 
El músico que en su casa escucha una sinfonía compuesta por otro y la registra, o simplemente la memoriza, no puede después reproducirla con sus instrumentos en $s u$ local sin el consentimiento del autor original. No puede, por tanto, dar a sus instrumentos y a su local el uso que estime oportuno.

El inventor de un nuevo carburador, valiéndose de su patente, no sólo posee un derecho de propiedad sobre los materiales en los que ha plasmado su idea, sobre su carburador, sino un derecho de control parcial sobre todos los carburadores existentes, cuyos propietarios no pueden aplicar esa innovación en $s u$ carburador sin el consentimiento del inventor ${ }^{18}$. Los propietarios de los carburadores antiguos no pueden hacer con $s u$ carburador lo que deseen, ya que al menos un uso concreto, la aplicación de esa invención, les está vedado. No pueden decidir con carácter exclusivo el fin a que van a destinar $s u$ carburador, pues con respecto a ese fin concreto es el inventor el que decide. Todos aquellos individuos que poseen las piezas para montar el nuevo carburador no pueden hacer uso de ellas con esa finalidad sin el consentimiento del inventor. El inventor posee por tanto un derecho de control parcial sobre todas esas piezas, ya que sus propietarios no pueden hacer con ellas simplemente lo que deseen, no pueden en particular reproducir ese carburador. De este modo, si como decíamos antes «en la medida en que no se respete este control de la persona sobre sus posesiones legítimamente adquiridas se estará violando su derecho de propiedad», los titulares de estos monopolios legales (copyrights y patentes), los que detentan un derecho de control parcial sobre la propiedad ajena con respecto a las ideas protegidas, violan el derecho de propiedad de terceros. El titular de la patente del carburador al que nos referíamos está violando el derecho de propiedad de aquellos que poseen el carburador y las piezas necesarias para reproducir la invención, pues no pueden hacer

18 Kinsella (2001). 
con su propiedad lo que estimen oportuno de acuerdo con sus fines particulares, no pueden destinar sus carburadores y sus piezas al fin concreto de reproducir la obra del inventor original, luego se están restringiendo-violando sus derechos de propiedad sobre sus piezas

Tomando un clarificador ejemplo de Stephan Kinsella: por el mero hecho de idear una nueva técnica para cavar hoyos, el inventor puede prohibir a todos los otros individuos del mundo cavar hoyos del mismo modo, incluso en su propiedad ${ }^{19}$. O como escribe Tom Palmer, la ejecución de un derecho de propiedad sobre una danza concreta, por ejemplo, implica emplear la fuerza para impedir a otro individuo mover su cuerpo de una determinada manera, luego se está restringiendo el derecho de propiedad de este individuo sobre su propio cuerpo ${ }^{20}$.

Así, en palabras de Kinsella: "por el solo hecho de pensar y plasmar un patrón original de información, o por el solo hecho de encontrar otra nueva manera de emplear su propiedad, el creador protegido por la propiedad intelectual deviene propietario parcial de las propiedades de los demás» ${ }^{21}$. De esta forma las patentes y los copyrights transfieren parcialmente derechos de propiedad de los poseedores naturales de bienes tangibles a los inventores, creadores y artistas, lo cual supone una violación de los derechos de propiedad de los primeros ${ }^{22}$. Los poseedores naturales, al reproducir en su propiedad una idea que ha sido concebida por un tercero, no atentan contra la integridad física o los bienes de nadie. Hacen un uso pacífico de su propiedad, en ningún momento impiden por la fuerza que el inventor destine la suya al fin que desee.

Por otro lado, como apunta el profesor Roderick Long, no es posible apropiarse de algo que no puedes controlar, y no puedes

\footnotetext{
19 Íbid.

20 Palmer (1990).

${ }^{21}$ Kinsella (2001).

22 Íbid.
} 
controlar aquello que está en la mente de los demás ${ }^{23}$. Luego carece de sentido pretender apropiarse de una idea que está ya en la mente de otro. Si un individuo ve cómo funciona el invento de un tercero, cómo funciona su carburador nuevo, por ejemplo, esa idea ya está en su cabeza y es absurdo alegar que pertenece al creador original del carburador. De donde se sigue que este individuo puede plasmar la idea que ahora reside en $s u$ mente en un material tangible que sea de $s u$ propiedad, fabricando otro carburador de iguales características.

En palabras del profesor Tom Bell, «al invocar el poder del Estado, el titular de un copyright o una patente puede imponer retención previa, multas, encarcelamiento y confiscación a aquellos que se expresan pacíficamente y que disfrutan con serenidad de su propiedad tangible. Porque esto amordaza nuestras voces, ata nuestras manos y echa abajo nuestras prensas, la ley de copyrights y patentes viola los mismos derechos que Locke defendió» ${ }^{24}$.

\section{Propiedad intelectual o derechos sobre bienes no escasos}

En economía se denomina bien escaso a aquel bien cuyo uso por parte de un individuo excluye / limita el uso de este bien por parte de otro individuo o para otra finalidad ${ }^{25}$. La escasez

23 Long (1995).

24 Bell (2002). Vale la pena ilustrar este argumento con un caso concreto que tuvo lugar en Estados Unidos en 1996. Ese año la ASCAP (la «American Society of Composer and Performers»), entidad gestora de derechos de autor por cuenta de 68.000 afiliados, requirió el pago de regalías a todos los campamentos de verano del país en los que los niños cantaran alrededor de la hoguera alguna de las cuatro millones de canciones amparadas por la entidad. La iniciativa suscitó airadas protestas, afectando la imagen pública de la ASCAP. Finalmente capituló y aceptó el pago simbólico de un dólar anual por campamento. Pero como apunta Julio Cole, lo grave es que este humilde pago simbólico ya supone un reconocimiento formal de las demandas de la ASCAP, a saber, que cualquier ejecución pública de una canción debe ser previamente autorizada por el autor, esto es, que los individuos no tienen derecho a expresarse con total libertad, pues les está vedado articular una determinada sucesión de vocablos en una determinada entonación. Cole (2003).

25 Hoppe (1989, p. 9). 
no alude en este sentido a la carencia o insuficiencia de algo, sino al hecho de que un bien sea de uso excluyente. Un bien es escaso cuando no puede ser usado indistintamente por varios individuos para sus respectivos fines. Surge así la posibilidad de conflicto. Una manzana, por ejemplo, es un bien escaso porque si alguien la engulle ningún otro individuo puede darle uso. Por tanto, puede haber conflicto sobre su uso por parte de múltiples actores humanos. Los rayos del sol, por el contrario, no son bienes escasos, no generan ningún tipo de conflictividad sobre su uso: el que alguien reciba luz del sol no impide / limita que otro la reciba y se aproveche también de ella. No hay conflicto posible sobre su uso, porque nada de lo que haga yo limita de algún modo el uso que otro puede hacer del mismo objeto. De la escasez deriva entonces la necesidad de articular una ética social que prescriba derechos de propiedad conformes con la naturaleza actuante del hombre, derechos de uso sobre los bienes escasos que soslayen el conflicto y permitan a cada individuo perseguir pacíficamente sus fines sin interferencias indeseadas. Tal es el fundamento de los derechos de propiedad lockeanos sobre bienes tangibles.

Las ideas, sin embargo, no son bienes escasos. Los objetos inmateriales no son de uso excluyente, no hay conflictividad en relación con su uso. Una idea puede reproducirse de forma simultánea en la mente de todos, puede ser utilizada por un individuo sin que ello impida / limite el uso de esa misma idea por parte de terceros. El uso de una idea particular por parte de un individuo no excluye / limita el uso de nadie con respecto a esa idea. Si alguien canta una canción, ello no impide que otro pueda cantarla. La canción no se gasta por muchas voces que la entonen y por muy a menudo que lo hagan. El que alguien utilice un invento no impide que otro pueda plasmar físicamente la misma idea innovadora y hacer igualmente uso de ella. El que un individuo escriba un libro no impide que otro exprese en una hoja de papel las mismas palabras. La ideas no son, 
pues, un bien escaso, luego no tiene sentido que se establezcan normas éticas para evitar el conflicto, ya que no puede haber conflicto alguno con respecto a su uso ${ }^{26}$. En el caso de la manzana hay conflicto sobre su uso: uno puede quejarse de que otro se la coma porque entonces ya no puede comérsela él. Pero en el caso de una receta de cocina o de una canción no hay conflicto posible sobre su uso, el individuo no puede alegar que si otro hace uso de tal o cual idea impedirá que él haga uso de la misma idea. Y si no hay conflicto sobre el uso de la receta de cocina o de la canción, ¿qué justificación tiene el derecho de propiedad? Con la manzana es preciso establecer un derecho de propiedad para ver quién puede comérsela legítimamente, pero con la receta o la canción eso no hace falta, porque todo el que quiera puede utilizarlas sin que ello las desgaste ${ }^{27}$.

${ }^{26}$ Las ideas, mientras no son difundidas y permanecen en la mente de su autor, más que de uso excluyente cabe considerarlas de uso exclusivo. La idea, per se, no es de uso excluyente o escasa. Puede «excluirse» a los demás de su uso en tanto no se revele, pero no en razón de la naturaleza misma de la idea. Puede excluirse a terceros porque no la conocen, pero no porque la idea en sí se gaste o tenga usos conflictivos (que es lo que define la escasez).

27 Es cierto que las ideas se plasman en objetos tangibles, y que la cantidad de éstos es limitada. Así, una idea para construir una autopista en un lugar concreto no puede materializarse, lógicamente, en ningún otro lugar. Esta idea sólo puede plasmarse una vez. ¿Significa ello que esta idea sí es escasa? Si alguien la plasma nadie más podrá hacerlo. ¿No es, por tanto, de uso excluyente? La respuesta es no, pues hay que entender que no es la idea la que es escasa, sino el bien tangible. Lo que es de uso excluyente no es la idea en sí, que como tal puede reproducirse en la mente de todos al mismo tiempo, sino el uso de ese bien tangible. Si el terreno en cuestión se emplea para construir la autopista propuesta no podrá utilizarse para hacer un parque o para hacer otro tipo de autopista. Es el terreno el que es de uso excluyente, el que es un bien escaso. Si hubiera más terrenos como éste la idea podría plasmarse en más sitios. Si en lugar de hacer referencia a un objeto concreto la idea hiciera referencia a algo más genérico, podría plasmarse con más frecuencia. La cuestión es que la idea per se no es escasa, lo son los bienes en los que se materializa, y en la medida en que éstos son específicos se reduce el número de objetos en los que puede aplicarse la idea. ¿Ha surgido aquí entonces algún tipo de conflictividad que no hayamos contemplado todavía? ¿No es acaso conflictiva la idea que quiere aplicarse en el terreno? Si se emplea esta idea ya no podrá aplicarse ninguna otra, y ésta no podrá volver a plasmarse en ningún otro lugar. Pero fijémonos que aquí lo que se discute no es el uso excluyente de la idea, sino el uso 
La propiedad privada en su sentido tradicional resulta de la escasez: sólo los bienes escasos son apropiables, pues sólo con respecto a su uso puede haber conflictos. Por el contrario, la propiedad intelectual no emana de la escasez sino que la genera artificialmente. Como indica Julio Cole, su propósito es crear escasez a través de un monopolio legal, un derecho exclusivo, que garantiza una renta monopolística a quien lo retiene ${ }^{28}$. Se convierte en escaso algo que antes no lo era. Una idea no es un bien escaso por naturaleza, sino que deviene escaso por efecto de la propiedad intelectual. Ésta no surge, por tanto, para evitar conflictos, ya que a falta de escasez son inexistentes; la conflictividad se origina artificiosamente adjudicando derechos exclusivos sobre algo que no puede ser objeto de un derecho exclusivo.

\section{Propiedad y recompensa}

Si no hay conflictividad posible sobre el uso de las ideas, ¿qué otra cosa podría justificar un derecho de propiedad sobre ellas? La respuesta intuitiva de mucha gente es que uno tiene derecho a gozar en exclusividad de los frutos de su creatividad intelectual. Se concibe la propiedad intelectual como un mecanismo para asegurar una merecida recompensa por el esfuerzo invertido. ¿Por qué un individuo debe tener un derecho exclusivo sobre el nuevo carburador que ha inventado? Porque es fruto de su trabajo, de su esfuerzo intelectual, y merece quedarse con él. Sin embargo, el esfuerzo y el mérito jamás han sido el fundamento del derecho de propiedad. No nos apropiamos de algo porque nos hayamos esforzado en conseguirlo o porque

excluyente del bien tangible, del terreno. Hay conflicto sobre el uso que puede darse a este terreno (construir esta autopista, un parque...), no sobre el uso de la idea. Por eso, porque hay un conflicto sobre el uso del terreno, es preciso establecer derechos de propiedad sobre el terreno, no sobre los fines a que puede destinarse.

${ }^{28}$ Cole (2001). 
nos lo merezcamos sino porque lo descubrimos y ocupamos / usamos en primer lugar o lo recibimos voluntariamente de un tercero. Es cierto que el esfuerzo y el mérito están estrechamente ligados a la apropiación y el enriquecimiento, pero no es en rigor el motivo por el cual devenimos propietarios de algo. Cuando cultivamos un campo yermo éste pasa a pertenecernos no porque merezcamos una recompensa o nos hayamos esforzado, sino porque lo hemos labrado antes que cualquier otro individuo. Cuando nos toca la lotería nos enriquecemos legítimamente, y nadie puede decir que eso sea el resultado de nuestro esfuerzo o que en efecto nos lo merezcamos. A lo mejor somos unos vagos y no hemos hecho nunca nada de provecho, y un día compramos un boleto y nos toca el gordo. ¿Alguien puede decir que nos hemos enriquecido como resultado de nuestro esfuerzo o porque nos lo merezcamos? No, y sin embargo está fuera de duda de que ha sido un enriquecimiento legítimo. Cuando heredamos una mansión, ¿podemos decir que deviene propiedad nuestra porque nos lo merezcamos o porque nos hayamos esforzado? No. Devenimos propietarios de la mansión porque ésa es la última voluntad de su legítimo propietario, no como recompensa por nuestro esfuerzo y trabajo. Puede ser cierto que hayamos trabajado duramente toda la vida, pero no es ese el motivo por el cual nos apropiamos de la mansión. Cuando alguien nos regala algo también devenimos propietarios del regalo y eso no tiene por qué corresponderse con nuestro esfuerzo o mérito. En ocasiones, por tanto, la gente se enriquece legítimamente sin que ello suponga una recompensa por su trabajo.

Por otro lado, muchas veces uno trabaja arduamente y no recibe la recompensa deseada. Ayudamos a nuestro vecino con la mudanza y sin embargo éste ni siquiera nos da las gracias. Invertimos todo nuestro tiempo en la construcción de una casa en el bosque y cuando ya está casi terminada una riada se la lleva por delante. Hacemos una monografía excelente para una 
asignatura de la universidad y el profesor nos pone un aprobado mediocre. La vida está repleta de ejemplos de esfuerzos no recompensados. Intentaremos siempre obtener lo que creemos merecer, pero no podemos decir que sea ilegítimo que no suceda así todas las veces. Por tanto, no es cierto que la propiedad sea una recompensa por nuestro esfuerzo. Puede serlo, y en la mayoría de casos así es, pero no es el esfuerzo o el mérito lo que nos convierte en propietarios.

En este sentido nuestra reacción cuando somos víctimas de un robo puede ser similar a la de cuando nos copian un invento o una idea que nos ha costado elaborar. No obstante, eso no significa que en el fondo creamos tener idéntico derecho de propiedad sobre ambos, sobre el bien tangible y sobre la idea. Si hemos estudiado mucho y en el examen uno de nuestros compañeros, que no ha estudiado nada, nos copia descaradamente y luego obtiene mejor nota que nosotros, puede que nos sintamos ultrajados, pero eso es porque esperábamos que cada cual fuera recompensado de acuerdo con su esfuerzo y su valía, no tiene nada que ver con el derecho de propiedad. Cuando nos copian un invento o una idea brillante, también podemos sentirnos agraviados, pero la razón no tiene que ver con el derecho de propiedad sino con la recompensa que esperábamos obtener por nuestro esfuerzo así como por el hecho de saber que otro se ha aprovechado de nosotros. Cuando nos roban un bien tangible también se aprovechan de nosotros, y de ahí que nuestra reacción sea similar. Pero mientras en el caso de un bien tangible sí nos une a él una sentimiento instintivo de pertenencia que en ocasiones va más allá del hecho de que creamos que es fruto de nuestro esfuerzo, en el caso de nuestras ideas lo que nos une a ellas es la expectativa de obtener una recompensa por nuestro esfuerzo. Sin embargo, como ya hemos visto, la propiedad no es per se una recompensa por nuestro esfuerzo, aunque habitualmente lo sea también. 


\section{Propiedad y control}

Sólo podemos apropiarnos, como hemos señalado, de aquello que podemos controlar, y no podemos controlar una idea que reside en la mente de los demás ${ }^{29}$. Una idea puede, por supuesto, mantenerse en secreto (caso de los secretos comerciales), pero una vez hecha pública no cabe alegar un derecho de control exclusivo sobre la misma, pues, de facto, está siendo «controlada» por los individuos que la han asimilado. Carece de sentido proclamarse propietario de esa idea, ¿acaso podemos obligar a los demás a no pensar en esa idea sin nuestro permiso? Un derecho de propiedad sobre un bien comporta un derecho a excluir a terceros del uso del bien poseído. Como propietarios de nuestra casa podemos impedir que otros accedan a ella. Si fuéramos propietarios de una idea deberíamos poder excluir a terceros de usar la idea, esto es, deberíamos poder impedir que pensaran en nuestra idea. Pero obviamente el pensamiento de los demás escapa a nuestro control. No podemos excluir a terceros de pensar en nuestra idea. Podemos, en efecto, impedir que la apliquen en algún bien tangible, pero eso supone un derecho de propiedad parcial sobre ese bien, no sobre la idea, pues se está excluyendo a los demás de usar el bien tangible para esa finalidad concreta, no se les excluye de usar/pensar en la idea en cuestión. Es el control de ese bien con respecto a esa finalidad lo que está en disputa, no el control de la idea, que puede estar en la mente de todos los individuos. Por tanto, y contrariamente a lo que sucede con los bienes tangibles, no cabe un control excluyente sobre las ideas reveladas, luego no pueden ser objeto de apropiación.

29 Long (1995). 


\section{Límites arbitrarios}

Desde una perspectiva de derechos naturales es de todo punto arbitrario distinguir entre descubrimientos no patentables e invenciones patentables. Se arguye, como apuntábamos en la definición de patente, que el descubrimiento científico o filosófico, la identificación de aquello que existe en la naturaleza, no es una creación y por tanto no es patentable ${ }^{30}$. Pero en este sentido nada es una creación, pues todo objeto es la recomposición de una materia ya existente de acuerdo con unas leyes naturales que descubrimos y aplicamos ${ }^{31}$.

Siguiendo a Roderick Long, las leyes de la naturaleza tienen diferentes grados de generalidad y especificidad. «Si es una ley natural que el cobre conduce electricidad, no lo es menos que este mismo cobre, configurado de una determinada manera, con otros materiales también configurados de una determinada manera, resultan en una batería»32.

Por otro lado, pecan igualmente de arbitrarios los límites temporales de la propiedad intelectual. En Estados Unidos la duración del copyright es de toda la vida del autor más 70 años después de su muerte ${ }^{33}$; la de las patentes, 20 años $^{34}$. En España la duración de los derechos de autor también es de 70 años después de la muerte del autor ${ }^{35}$. ¿Por qué 70 años después de su muerte y no 50? ¿Por qué no 20 años desde el registro de la autoría? ¿O cinco años desde el registro de la invención? ¿De dónde puede deducirse el límite temporal adecuado? La

30 Spooner, en su afán por ser consecuente, estimaba apropiables tanto los descubrimientos científicos o naturales (hoy no patentables) como las invenciones plasmadas materialmente. Spooner (1855).

31 Kinsella (2001).

32 Long (1995).

33 Cole (2003).

${ }^{34}$ Kinsella (2001).

35 Ley de la Propiedad Intelectual, Real Decreto Legislativo 1/1996 de 12 de abril, Libro I (De los derechos de autor), Título III, Capítulo I, Artículo 26. 
arbitrariedad de la duración de la propiedad intelectual es palmaria, luego en todo caso sólo puede obedecer a criterios utilitaristas. En realidad atiende más bien a criterios partidistas. A lo largo de los últimos dos siglos en Estados Unidos los límites temporales del copyright se han ido dilatando paulatinamente: de 14 años en 1790 (renovable por otros 14) se ha pasado en 1998, después de sucesivas enmiendas a la ley de copyright, a toda la vida del autor más 70 años (95 años en el caso del copyright corporativo), por lo que la temporalidad que prescribía la constitución americana se ha tornado en un mero formalismo ${ }^{36}$. Claramente el propósito de estas sucesivas revisiones no ha sido el de incentivar el progreso, sino el de prolongar monopolios legales muy rentables para determinadas empresas ${ }^{37}$.

Una última consideración, relevante en el caso de las patentes: ¿qué sucede si dos individuos inventan, de forma independiente, en momentos distintos del tiempo, un mismo dispositivo ${ }^{38}$ ¿En razón de qué se confiere al primer inventor un derecho exclusivo sobre el uso de ese objeto si el segundo inventor, aunque lo haya creado más tarde, lo ha hecho de modo absolutamente independiente, sin saber de la existencia del anterior? Si lo que justifica una patente es el acto de creación genuino, original, ¿qué hace que al primero se le otorgue el monopolio legal sobre el invento y al segundo se le niegue todo

36 Cole (2003). Entre los poderes del Congreso la constitución estadounidense cita «el fomento del progreso de la ciencia y las artes útiles, otorgando por un período limitado de tiempo a autores e inventores un derecho exclusivo sobre sus obras y sus descubrimientos». Constitución de los Estados Unidos, artículo 1, sección 8.

37 Cole (2003). La ley Sonny Bono, una serie de enmiendas a la Ley de derechos de autor, fue impulsada, por ejemplo, por firmas vinculadas a la industria cinematográfica que querían evitar, con la extensión del límite temporal, que varios de sus personajes pasaran al dominio público. El caso de Disney, una de la compañías promotoras de esta ley, resulta paradójico, pues históricamente se ha beneficiado de personajes y relatos que eran de dominio público: Blancanieves, Pinocho, La Sirenita, El Libro de la Selva, El Jorobado de Notre Damme... Íbid.

38 Long (1995). 
derecho? Una legislación coherente en este sentido debiera permitir que hubiera tantos titulares de una patente o copyright como autores independientes (lo cual a efectos prácticos puede resultar problemático y puede menoscabar la creación de monopolios legales para incentivar la innovación).

El único modo de superar estas arbitrariedades es borrando las fronteras artificiales y convertir en ilimitado el monopolio legal, ilimitado en cuanto al tipo de ideas que pueda abrigar e ilimitado en cuanto a su duración temporal. Así, cualquier idea podría ser patentable u objeto de copyright y el derecho exclusivo sería perpetuo. El precio de esta coherencia superficial sería la paralización del progreso: si cada vez que encendiéramos una bombilla tuviéramos que pedir permiso o pagar royalties a los herederos de Edison, si cada vez que empleáramos una idea (desde una fórmula científica hasta una nueva técnica para recolectar frutos o construir casas) tuviéramos que pedir autorización y pagar por ella el desarrollo se detendría y la humanidad fallecería de hambre. Una ética que produjera este resultado claramente estaría viciada en algún punto, pues no parecen ajustarse a la naturaleza humana unas normas que impiden al hombre superar su estado de indigencia natural ${ }^{39}$.

39 Virtualmente ningún valedor de la propiedad intelectual ha defendido esta postura tan extrema. Andrew Joseph Galambos sería una de las pocas excepciones. Llegó a reivindicar, por ejemplo, un derecho exclusivo sobre sus ideas tal que exigía a sus alumnos que no las repitieran fuera de clase sin su permiso, pues sólo a él pertenecían. Galambos al parecer también cambió su nombre original Joseph Andrew por el de Andrew Joseph, para no infringir el derecho de su padre a su propio nombre. Véase Kinsella (2001) y Browne (1997). Lysander Spooner, asimismo, llevó hasta las últimas consecuencias su defensa de la propiedad intelectual, sosteniendo la legítima apropiación tanto de principios científicos o naturales descubiertos como de inventos plasmados físicamente, así como la perpetuidad de dicho título. Véase Palmer (1990). 


\section{PERSPECTIVA ECONÓMICA}

El utilitarismo pretende la maximización del bienestar social o la utilidad social, esto es, el mayor bienestar para el mayor número ${ }^{40}$. Se prescriben normas o políticas, pues, en función de si van a reportar de forma agregada más utilidad social, y no atendiendo a si están o no en sintonía con unos abstractos derechos naturales del hombre. Los derechos, para el utilitarismo, son más bien construcciones ad hoc convenientes para alcanzar esa anhelada maximización del bienestar ${ }^{41}$.

Los proponentes utilitaristas de la propiedad intelectual arguyen, de esta suerte, que la riqueza, el progreso, será optimizado (o aumentará) si se garantizan copyrights y patentes que incentiven la labor de autores y inventores ${ }^{42}$. No se contempla si los creadores tienen en efecto un derecho natural sobre sus obras. Desde un punto de vista estrictamente utilitarista esto es irrelevante, lo único que interesa es si la propiedad intelectual fomenta el progreso. A este planteamiento cabe oponerle dos críticas generales:

En primer lugar, no es aceptable que el utilitarismo prevalezca por encima de la ética de los derechos naturales, pues en aras de la maximización del bienestar para la mayoría pueden cometerse los más obscenos atropellos contra individuos y minorías. Si ningún derecho protege a las personas a priori,

40 Palmer (1990).

41 Cabe apuntar que aquí no estamos contraponiendo el utilitarismo con el liberalismo, sino el utilitarismo con el iusnaturalismo, el utilitarismo con los derechos naturales. El utilitarismo bien entendido (encuadrado en la noción de eficiencia dinámica) es perfectamente defendible desde un punto de vista liberal (de hecho justicia y eficiencia son a este respecto conceptos complementarios, el conflicto entre ambos es sólo aparente). Véase Huerta de Soto (2004, p. 52).

42 «Es menos probable que una empresa invierta recursos en desarrollar un nuevo producto si empresas competidoras que no han incurrido en este gasto puede duplicar el producto y producirlo al mismo coste marginal que el innovador; la competencia reducirá el precio hasta el coste marginal y el coste de la inversión no será recuperado». Landes y Posner (2003, p. 13). 
todos nos hallamos a merced de lo que presuntamente sea útil, beneficioso, para los demás. Si a la mayoría le complace vernos sufrir, el utilitarismo no puede hacer otra cosa que suscribir que nos torturen para «maximizar el bienestar de la sociedad». Conclusiones de este tipo dudosamente serían aceptadas por los propios utilitaristas ${ }^{43}$. Por otro lado, puesto que lo que se considera es únicamente el resultado de un proceso se da la circunstancia de que puede tildarse de justo o injusto un escenario con independencia de cuál haya sido el comportamiento de los individuos en el proceso ${ }^{44}$. Esto supone una subversión de los principios de justicia tradicionales, pues no se evalúan las acciones de los individuos por sí mismas sino a la luz de un determinado óptimo teórico.

En segundo lugar, el utilitarismo carece de consistencia científica en tanto se erige sobre postulados irreales pretendiendo calcular «óptimos sociales» al margen de las elecciones efectivas de los individuos en el mercado. Sus premisas para maximizar el bienestar social simplemente no se atienen a la realidad, pues las utilidades de cada persona no son mesurables ni pueden agregarse para conformar óptimos sociales. Las valoraciones subjetivas de los individuos son de carácter ordinal (un individuo prefiere A antes que B), no de carácter cardinal (A vale para un individuo 30 unidades de utilidad y B sólo vale 10 unidades de utilidad), por lo que no pueden sumarse o restarse entre ellas ni cabe hacer comparaciones interpersonales de utilidad ${ }^{45}$. Toda comparación interpersonal de utilidad es científicamente ilegítima, no hay modo de determinar que la

43 Para una crítica iusnaturalista del utilitarismo véase Rothbard (1982, pp. 275-282).

44 «(P)retende enjuiciar como justos o injustos los resultados específicos del proceso social en determinados momentos históricos con independencia de que el comportamiento de los artífices del mismo se haya adaptado o no a normas jurídicas y morales de carácter general.» Jesús Huerta de Soto, citado en Kirzner (1989, p. 27).

45 Rothbard (1956). 
sociedad se beneficia más de la tortura de alguien de lo que éste sufre por ella, pues quizás su pena es infinita y cada individuo extrae muy poca satisfacción del hecho de verle torturado. No hay modo de establecer cuánto se «benefician» unos y cuánto «pierden» otros, no hay modo de cuantificar y comparar las utilidades de unos y otros y calcular de este modo si se ha producido un aumento de la utilidad global, del bienestar del conjunto, o un descenso. La utilidad percibida por un individuo es una apreciación subjetiva más o menos intensa psicológicamente a la cual no cabe asignar ningún número cardinal. Nos sentimos muy satisfechos o poco, pero no sabemos cuánto ni hay modo de comparar científicamente esta satisfacción nuestra con la satisfacción de los demás ${ }^{46}$. En este contexto, las transacciones en el mercado son siempre pareto-óptimas en el sentido de que todas las partes mejoran su situación al desprenderse de algo que valoran menos, ex ante, que lo que van a recibir a cambio. Cuánto más se benefician unos que otros o cuánto menos se benefician de lo que podrían haberse beneficiado de haberse configurado otro tipo de arreglos es una cuestión que desde un punto de vista científico no tiene sentido plantearse. Ex ante, la asignación ha sido óptima o eficiente porque todos los participantes han actuado conforme a sus valoraciones subjetivas y han mejorado su posición sin que nadie haya visto empeorar la suya ${ }^{47}$. Todos los participantes en el mercado han elegido lo que han preferido, puesto que han actuado voluntariamente. Si, actuando voluntariamente, hubieran preferido otra alternativa de entre las disponibles, la hubieran elegido. Al decidirse por una alternativa concreta y no por

46 Íbid.

47 Es decir, antes de satisfacer el fin el individuo escoge el medio que cree que satisfará mejor un determinado fin (es una valoración previa a la satisfacción del fin). Ex post, después de la transacción y al hacer uso del medio, el individuo puede darse cuenta de que no sirve para satisfacer ese fin (error empresarial). Por eso decimos que la asignación siempre es óptima ex ante. 
otra decimos que han demostrado su preferencia por esa alternativa ${ }^{48}$. Aseverar que alguien, a pesar de haber elegido la alternativa $X$, prefiere en realidad la alternativa $Z$ es negarse a hacer ciencia. Si el individuo ha elegido $X$ en lugar de $Z$ es porque en ese momento prefería, por el motivo que fuera, $X$ a $Z$, de lo contrario hubiera hecho la elección contraria.

Los proponentes utilitaristas de las patentes y los copyrights sostienen que la implementación de esto monopolios legales favorece un resultado óptimo, al generar incentivos para canalizar recursos hacia la invención y la creación. Pero los recursos empleados en la invención y la creación son recursos que dejan de emplearse en otro sitio. ¿De dónde se sigue que esta redirección de recursos «maximiza la utilidad social»? Si la propiedad intelectual es un artificio del Estado, no puede decirse que en su ausencia el resultado de las acciones libres de los individuos sería subóptimo. Los recursos se destinarían a una rama productiva o a otra en función de las preferencias de los individuos en el mercado. Interferir en este proceso de interacciones voluntarias instituyendo monopolios legales sólo limita la capacidad de cada uno de actuar de acuerdo con sus preferencias particulares.

Expuestas estas consideraciones previas, vayamos a criticar el núcleo de la argumentación utilitarista-económica en pro de las patentes y los derechos de autor. Se alega, como hemos visto, que la propiedad intelectual fomenta el progreso. El argumento económico es el siguiente: garantizar a autores e inventores derechos exclusivos sobre sus obras incentiva la creación, esto es, los autores y los inventores tienen incentivos para crear porque sólo ellos acapararán los beneficios de explotación de su obra. Si no se les concediera este monopolio legal, si no

48 «El concepto de preferencia demostrada es simplemente esto: que una elección real revela, demuestra, las preferencias de un individuo; es decir, que sus preferencias son deducibles a partir de lo que elige actuando.» No confundir con el concepto de preferencia revelada de Samuelson, que tiene otras implicaciones. Rothbard (1956). 
se les asegurara la obtención de los ingresos por la comercialización de su obra, entonces carecerían de incentivos para crear; el autor que fuera a escribir un libro no tendría garantías de que sólo él podría explotarlo comercialmente, luego quizás no lo escribiría; el inventor que se dispusiera a diseñar un nuevo carburador no tendría garantías de que sólo él podría darle uso, otros podrían recoger su idea y hacerle la competencia en el mercado, luego quizás no lo inventaría. Por tanto, sin propiedad intelectual los incentivos se reducirían y, en consecuencia, el progreso se resentiría gravemente. Habría menos obras y menos inventos. La conclusión utilitarista es que la propiedad intelectual instituye incentivos para fomentar el progreso, para maximizar la riqueza, y que por este motivo están justificados ${ }^{49}$.

A continuación veremos por qué es discutible que los beneficios de la propiedad intelectual sean en realidad tan elevados como sus valedores alegan, y por otro lado, por qué es posible que los ingentes costes de la propiedad intelectual (aquellos beneficios a los que se ha renunciado al instituir la propiedad

49 Se arguye también que las ideas son un ejemplo de «bien público» por ser bienes no-rivales en el consumo (el que una persona consuma el producto no disminuye el consumo que otra persona pueda hacer del mismo producto) y que no permiten la exclusión de los no-compradores. Esto generaría un efecto free-riding: numerosos individuos «supuestamente» interesados en el bien se abstendrían de pagar por él a la espera de que lo hicieran otros, pudiendo aprovecharse entonces de éste gratuitamente; la generalización del fenómeno acarrearía que el bien se produjera finalmente en una cantidad menor de la que sería necesaria para satisfacer a los interesados (el mercado ocasionaría un resultado subóptimo). El hecho de que una innovación genere «externalidades positivas», de que los beneficios de una nueva idea (un invento, un libro, una canción...) no puedan cargarse sobre todos los consumidores, produciría el mencionado efecto free-riding (numerosos individuos copiarían el invento, el libro o la canción en lugar de comprarlo, por ejemplo, pero al obtener los autores y creadores menos ingresos producirían menos inventos, menos libros y menos canciones), lo cual exigiría que el Estado interviniera para corregir el mercado (las elecciones libres de los individuos) y maximizar la utilidad social. En el párrafo anterior y en apartados posteriores impugnamos la solidez de esta tesis. Para una crítica al concepto de bien público véase Esplugas (2006). 
intelectual) pueden incluso eclipsar los supuestos beneficios de esta regulación ${ }^{50}$.

Relativizando los beneficios:

- En primer lugar, no todo el incremento de la productividad es resultado de invenciones; también se debe a economías de escala, mejoras en la calidad de la fuerza del trabajo, cambios demográficos... Además, no todo el progreso técnico atribuible a las invenciones es resultado de invenciones patentadas. Éstas conforman sólo una fracción de las invenciones, y una fracción de una fracción de la productividad en su conjunto ${ }^{51}$. Diversos tipos de objetos ideales no están amparados por la legislación de patentes y copyrights, y sin embargo se producen constantes innovaciones en esos ámbitos también (en el de la moda, por ejemplo, o en el de las estrategias de marketing o el de los principios científicos y fórmulas matemáticas) ${ }^{52}$.

- Numerosas invenciones y creaciones no se han producido como resultado de los incentivos que instituye la propiedad intelectual. En el ámbito de las patentes los estudios empíricos dirigidos por Edwin Mansfield son ilustrativos. En un primer estudio se concluye que, exceptuando los medicamentos, la ausencia de la protección de patentes hubiera afectado a menos de una cuarta parte de las innovaciones de la muestra (es decir, la mayoría se hubiera producido igualmente). En un segundo estudio, de acuerdo con una muestra de 100 compañías de 12 industrias distintas, sólo los empresarios de dos industrias consideraron que las patentes fueron esenciales para un tercio o más de sus innovaciones. En siete industrias, por

50 Cole (2001).

51 Íbid.

52 En Estados Unidos, Palmer (1989). 
otro lado, los empresarios estimaron que las patentes sólo fueron esenciales para el desarrollo de menos del 10\% de sus invenciones. En algunas de estas industrias incluso se consideró que las patentes no fueron necesarias para el desarrollo de ninguna de sus innovaciones ${ }^{53}$. Atendiendo al historiador Thomas Ashton, la Revolución Industrial hubiera acaecido igualmente en ausencia de propiedad intelectual. De hecho, apunta Ashton, se inició cuando expiró la patente de Watt sobre la máquina de vapor ${ }^{54}$. Del mismo modo, en el siglo XIX en Estados Unidos los autores foráneos no gozaban de la protección del copyright y, no obstante, existía un mercado de obras extranjeras. Editores y autores arbitraron mecanismos voluntarios y contractuales para posibilitar un negocio lucrativo ${ }^{55}$.

Considerando los costes:

- Los gastos inherentes a la propiedad intelectual en materia de registros, trámites, asesoría, tribunales, abogados etc. obviamente no tendrían lugar en un escenario sin patentes y copyrights, luego los recursos empleados a este respecto se destinarían a otros fines más productivos ${ }^{56}$. En este contexto cabe señalar que las empresas a menudo juzgan más rentable invertir en tácticas legales para proteger sus invenciones que invertir propiamente en la investigación y el desarrollo de nuevas ideas, por lo que el gasto en asesoría y abogados es muy abultado ${ }^{57}$.

53 Cole (2001).

54 Íbid.

55 Palmer (1989).

${ }^{56}$ Kinsella (2001).

57 En palabras de Sharon Levine, director ejecutivo de la HMO Kaiser Permanente: «Hoy en día los consumidores están pagando una prima extraordinaria creyendo que están promoviendo la innovación del futuro. Pero en realidad están financiando abogados». Boldrin y Levine (2005). 
- La introducción de barreras de entrada (monopolios legales) restringe la competencia, lo cual puede comportar menos innovación y precios más elevados para los consumidores. A Henry Ford se le impidió inicialmente desarrollar sus automóviles porque ALAM retenía las patentes sobre los coches de gasolina. En el campo de la aviación sucedió algo similar: los hermanos Wright patentaron un mecanismo especial para las alas del avión y demandaron a todos los que intentaron aplicar innovaciones parecidas $^{58}$. Según Johann Murmann, las empresas de tinta sintética en Suiza y Alemania durante el perído 1857-1914 desarrollaron una tecnología más avanzada que sus homólogas británicas o francesas porque inicialmente carecían de patentes y estaban sujetos a una mayor competencia en los mercados internos ${ }^{59}$. Los monopolios legales sobre un determinado conocimiento también limitan severamente las posibilidades de investigación en torno a éste. El hecho de circunscribir el uso de una idea a una sola empresa menoscaba, por tanto, la emergencia de nuevos conocimientos. Por otro lado no puede saberse de antemano si las posibilidades de investigación de una invención patentada exceden la capacidad de la empresa para llevarlas a cabo ${ }^{60}$. En el caso de las industrias cuyas innovaciones se apoyan continuamente en innovaciones anteriores, la introducción de patentes puede que dificulte más que incentive la creación (el incentivo a la creación puede verse más que compensado por la dificultad de innovar a partir de conocimientos existentes) ${ }^{61}$.

- Con el objeto de esquivar una patente numerosas empresas inventan alrededor de ella, ofreciendo un producto lo

\footnotetext{
58 Cole (2001).

59 Boldrin y Levine (2005).

60 Debo esta última reflexión a José Carlos Rodríguez.

61 Boldrin y Levine (2005).
} 
suficientemente diferenciado como para que no entre en conflicto con ésta. De este modo, para no infringir la patente de un tercero, se incide en un gasto superfluo y en ocasiones se produce un invento que, por ser algo distinto, resulta inferior al original ${ }^{62}$. Esta práctica también puede afectar a la compatibilidad entre bienes manufacturados (la diferenciación puede hacerlos incompatibles) ${ }^{63}$. Asimismo, los que retienen la patente incurren a menudo en gastos superfluos al inventar ellos también alrededor de ésta, para blindarse contra la competencia impidiendo que otros puedan esquivar su patente. IBM, por ejemplo, gastó millones de dólares en inventar alrededor de las patentes de Xerox, de modo que cualquier aspecto de su tecnología quedara protegido. Esto explicaría por qué el 25\% del presupuesto de IBM se destinó a la asesoría en materia de patentes y no a la investigación y al desarrollo ${ }^{64}$.

- Los copyrights y las patentes pueden enjuiciarse desde un ángulo distinto, a saber, ¿qué incentivos tiene un autor o un inventor para seguir creando si ya goza de una renta monopolística con respecto a su obra por un lapso muy dilatado de tiempo? Si un autor tiene garantizada una renta monopolística por un largo período de tiempo, ¿no se verán reducidos sus incentivos para seguir creando durante ese período? En contraposición, si carece de un monopolio legal y aspira a percibir un flujo constante de ingresos puede verse compelido a crear sin interrupción. El caso de Eastman Kodak es ilustrativo: con el propósito de mantener su liderazgo practicó una estrategia de innovación continua. Si hubiera sido capaz de proteger efectivamente sus patentes es posible

\footnotetext{
62 Cole (2001).

63 Palmer (1989).

${ }^{64}$ Cole (2001).
} 
que hubiera destinado menos recursos a la investigación y al desarrollo ${ }^{65}$. Puede que sea pertinente citar aquí las palabras de Michael Tiemann, vicepresidente de Red Hat: «cada vez que surge una patente de software es una promesa de que la innovación en este campo cesará durante 20 años»66. Como apunta Murray Rothbard, si de un lado las patentes sobre-estimulan el gasto en investigación en las etapas previas al registro de la patente, de otro lado desincentivan el gasto en investigación en el periodo posterior al registro ${ }^{67}$.

- Cabe considerar que las patentes quizás no fomenten un mayor progreso en general, sino que promuevan la innovación en una área concreta en detrimento de otra. En palabras de Milton Friedman, «hay muchas 'invenciones' que no son patentables. El 'inventor' del supermercado, por ejemplo, reportó grandes beneficios a sus congéneres por los cuales no podía cargarles un precio. En la medida en que una misma habilidad es requerida tanto por un tipo de invención como por otro, la existencia de las patentes tiende a desviar la actividad hacia las invenciones patentables» ${ }^{68}$. Así pues, las patentes distorsionarían la estructura de incentivos, trasladando la actividad de las áreas patentables a las áreas no patentables. Las patentes no afectarían al gasto total en investigación sino al tipo de gasto realizado ${ }^{69}$.

En definitiva, como concluye Julio Cole, quizás no habría menos invenciones en un contexto sin propiedad intelectual, sino simplemente otro tipo de invenciones ${ }^{70}$.

\footnotetext{
65 Íbid.

${ }^{66}$ Krill (2005).

67 Rothbard (1962, pp. 658-659).

68 Cole (2001).

${ }^{69}$ Rothbard (1962, pp. 658-659).

70 Cole (2001).
} 


\section{PROTECCIÓN CONTRACTUAL $V S$. DERECHOS RESERVADOS}

Las invenciones y las obras artísticas pueden protegerse legítimamente por la vía contractual, estableciendo compromisos que vinculan a las partes en lugar de privilegios otorgados por el Estado en forma de monopolios legales que vinculan a todos.

De acuerdo con la teoría de contratos sobre títulos de propiedad transferibles ${ }^{71}$, una propiedad $X$ que pertenece al individuo $B$ pasa a ser del individuo $C$ si un acuerdo entre ambos estipula que $X$ deviene, tras la firma, posesión de C. De este modo se transfieren contractualmente los títulos de propiedad. $\mathrm{X}$ deviene propiedad de $\mathrm{C}$ tan pronto como $\mathrm{B}$ y $\mathrm{C}$ así lo determinan y lo formalizan. El contrato es de este modo el consentimiento formalizado de las partes, y la transferencia, el resultado de ese consentimiento. Dicho esto, las transferencias de títulos también pueden ser condicionadas: imaginemos, por ejemplo, que el contrato dispone que B sólo transfiere la propiedad de 1000 euros a $C$ si $C$ realiza una determinada labor. En el caso de que $\mathrm{C}$ no acometa esta labor no tendrá derecho alguno sobre los 1000 euros; en el caso de que realice la labor tendrá derecho a los 1000 euros de B (en virtud del consentimiento de B expresado en el contrato). En otras palabras, si el contrato establece que 1000 euros de B devienen propiedad de C si se cumple la condición $Z$, tan pronto como se cumpla la condición $Z$, los 1000 euros devienen propiedad de C. Si no se cumple la condición $Z$ entonces $C$ no entra en posesión de los 1000 euros. Por otro lado, si se cumple la condición Z y el individuo B retiene los 1000 euros, B estará ahora reteniendo ilegítimamente una posesión de C (pues, recordémoslo, los 1000 euros devenían propiedad de $C$ si la condición $Z$ se cumplía, y se ha cumplido). La propiedad se transfiere en razón del

71 Véase Evers (1977), Kinsella (2003) y Rothbard (1982, pp. 191-213). 
consentimiento de las partes y los contratos son una forma de expresar ese consentimiento. Si el consentimiento expresado en el contrato es condicionado a algo, en la medida en que no se cumpla esa condición no habrá consentimiento y no se hará efectiva la transferencia de títulos de propiedad.

De este modo el autor de un libro o el creador de un invento puede extender un contrato por el cual concierta con los compradores una transferencia condicional de su obra (del bien tangible que la contiene), de forma que estos pueden quedar obligados contractualmente a no realizar copias del escrito, de la película o del nuevo carburador. El inventor puede traspasar su nuevo carburador (bien tangible) con la condición de que el comprador no haga copias, no lo ceda a terceros, no revele su composición etc. de modo que el carburador sólo deviene propiedad del comprador en tanto se cumpla ese condicionante. En el caso de que lo incumpla el comprador estará en posesión ilegítima del carburador (pues el título de propiedad se transfería sólo si se cumplía la condición), estará en posesión de un bien tangible que no le pertenece.

Pero el contrato sólo vincula a las partes, no a terceros. Si el autor de una canción protegida la canta por la calle y otro la registra, el autor luego no puede impedir que este individuo haga con la canción registrada lo que quiera, pues ninguna condición contractual obliga a éste en ningún sentido. Si un individuo abandona un libro que ha comprado bajo la condición de no hacer copias, aquel que lo encuentre no está obligado por contrato alguno en lo que respecta a la distribución de copias.

La diferencia entre el tipo de protección contractual esbozada aquí y los derechos reservados propios del copyright es que el primero vincula sólo a las partes contratantes mientras que el segundo vincula a todos, prescindiendo de si se han sometido o no a un contrato. Para Murray Rothbard, por ejemplo, el autor/inventor puede transferir su obra original sin que ésta contenga el derecho de copia (copyright), esto es, reser- 
vándoselo para sí 72 . El inventor del nuevo carburador puede transferirlo a condición de que no se copie, de manera que todas las copias que se hagan del original son ilegítimas, independientemente de que quien las haga sea parte contratante o no. El carburador traspasado no lleva consigo el derecho de hacer copias, de modo que si se hace una copia, ésta es ilegítima, y si se hace una copia de esta copia, también, y así sucesivamente. Si desde un principio no se cede el derecho de copia cualquier copia que derive en última instancia del objeto original con los «derechos reservados» será ilegítima. Esta tesis, sin embargo, trasciende el ámbito contractual para abrazar de nuevo la propiedad sobre las ideas. No es una aplicación de la teoría de contratos, sino una aplicación de la propiedad intelectual. Si un tercero no vinculado por contrato alguno no puede hacer uso de un bien tangible suyo para copiar el bien original (siendo su bien tangible distinto del bien tangible original) es que el autor/inventor retiene un derecho de propiedad sobre la idea plasmada en el bien material. Pero lo que era objeto de transferencia contractual presumiblemente era el bien tangible original, no la idea per se. El hecho de considerar que el copyright vincula a todos no puede explicarse, pues, en razón de la teoría de contratos sino en razón del concepto de propiedad intelectual. La diferencia entre el individuo que copia habiendo rubricado un contrato y el individuo que copia sin haber suscrito ninguno debería quedar clara. Si el individuo que ha comprado el nuevo carburador bajo la condición de no copiarlo etc. lo copia, deja de ser propietario de ese carburador y pasa a retener algo que no le pertenece (pues el propietario original solo consentía en traspasarlo si cumplía con la condición). Pero el individuo que no ha firmado contrato alguno $y$, habiendo visto el nuevo carburador, lo reproduce con piezas de $s u$ propiedad, no retiene nada que no le pertenezca. Está empleando sus

72 Rothbard (1982, p. 209). 
bienes tangibles, distintos de los que el propietario original transfirió al comprador.

El ejemplo del libro abandonado que citábamos más arriba puede resultar esclarecedor en este contexto. Imaginemos que un autor vende su libro a un individuo a condición de que no haga copias ni lo distribuya a terceros para que lo copien ellos, pero no dice que no pueda abandonarlo. El comprador acata las condiciones, si bien cuando termina de leer el libro en un parque le parece tan nefasto que decide abandonarlo allí mismo. Tiempo después un tercer individuo, que no tiene ninguna relación con los anteriores, llega al parque y se encuentra con el libro abandonado, deviniendo así su legítimo propietario. ¿Qué contrato obliga a este individuo a no realizar copias del libro o a no distribuirlo a otras personas para que lo copien ellas? Ninguno. Este individuo no ha firmado ningún contrato, de modo que puede hacer con su propiedad lo que quiera. Es cierto que en el contrato también podría estipularse la condición de que en el caso de que la propiedad se abandonase ésta volvería a su dueño original. Pero el ejemplo expuesto, en el que se omite dicha condición, sirve para ilustrar que un tercero que no ha firmado el contrato no tiene ninguna de las obligaciones que sí tenía el comprador.

Es preciso señalar que el hecho de que el origen último de una copia sea una violación de contrato no invalida el título de propiedad sobre la copia por parte de terceros no vinculados por un contrato. Supongamos que el autor de un libro lo vende a condición de que no se copie y el comprador lo copia y distribuye la copia. El comprador claramente ha violado el contrato y puede exigírsele restitución por ello. ¿Pero qué sucede con las copias que están en manos de terceros? Esas copias, que tienen su origen en la violación del contrato por parte del comprador, son propiedad de sus tenedores actuales, a quienes no vincula contrato alguno. Pueden hacer con ellas lo que deseen. El autor del libro tenía un derecho de 
propiedad sobre el ejemplar original vendido al comprador (de modo que al violarse el contrato el autor puede reclamarlo para sí), pero no tiene ningún derecho de propiedad sobre las copias. Los titulares de las copias no han violado ningún contrato (no habían firmado ninguno), y no están en posesión de ningún ejemplar que pertenezca al autor original (están en posesión de los ejemplares copiados). El autor es propietario del bien tangible original en el que se han plasmado sus ideas, no de los bienes tangibles en los que se han copiado sus ideas, pues ello significaría que retiene un derecho de propiedad sobre sus ideas (propiedad intelectual) y no únicamente sobre el bien tangible en el que las ha plasmado originalmente.

La violación de contrato que se produce al distribuir copias afecta al comprador atado por el contrato, no a los que ahora disponen de estas copias. Es muy cierto que los que ahora poseen las copias se han beneficiado de ese acto ilegítimo del comprador (la violación de contrato), pero eso no invalida su título. Imaginemos que un individuo ha inventado una fórmula rejuvenecedora y la guarda en su caja fuerte porque no quiere compartirla con nadie. Está, sin duda, en su derecho. Ahora supongamos que un ladrón roba la fórmula y la imprime en un millón de panfletos que luego lanza sobre la ciudad desde un avión. La gente de la calle recoge los panfletos, percatándose de la finalidad y la composición de esta fórmula. En realidad es una fórmula sencilla que todos podrían reproducir en su casa con sólo mezclar unos cuantos ingredientes y someterlos a cierto tratamiento. ¿Sería ilegítimo que lo hicieran? ¿Debería impedirse por la fuerza que los ciudadanos se valieran del nuevo conocimiento que ahora tienen de la fórmula? El ladrón sin duda violó los derechos del inventor al usurpar su secreto, ¿pero qué derechos violan los ciudadanos que ahora disponen de esta fórmula? ¿Tienen que dejar de utilizar su nuevo conocimiento sólo porque su origen es ilegítimo? Analicemos esta 
cuestión tomando un ejemplo de Stephan Kinsella ${ }^{73}$ : imaginemos que un individuo, Jed, descubre un yacimiento de petróleo bajo su propiedad. Nadie más se ha percatado de que hay petróleo en la zona, así que Jed se propone comprar todas las propiedades circundantes a precios irrisorios. Pero uno de sus suspicaces vecinos, Cooter, irrumpe ilegítimamente en su propiedad y descubre la verdad. Acto seguido llama al Wall Street Journal para revelar la existencia del yacimiento y al día siguiente el preciado secreto de Jed es vox populi. Los vecinos ahora demandan sumas millonarias por sus terrenos, truncando los planes de Jed, y todo a raíz de la actuación ilegítima de Cooter. Cooter obviamente es encausado por allanamiento, ¿pero puede impedirse por la fuerza que los vecinos de la zona procedan de acuerdo con su nuevo conocimiento elevando los precios de sus terrenos? ¿No es acaso ilegítimo el origen de esa información? ¿Tendrían que hacer como si no supieran que en realidad allí hay un yacimiento y venderle las propiedades a Jed por el precio que pensaban proponerle antes? Obviamente no. Los vecinos no han hecho nada ilegítimo. Las ideas no son apropiables y los vecinos no han obtenido la información de forma ilegítima (Cooter sí, pero ellos no), motivo por el cual pueden hacer con ella lo que deseen.

De esta manera, es ilegítimo que el comprador de una canción protegida por contrato la cuelgue en Internet. Pero los individuos terceros que se la descargan no tienen ningún vínculo contractual con el vendedor, y ni siquiera conocen al copiador. Simplemente utilizan una información disponible que no es apropiable para plasmarla en, por ejemplo, un CD de su propiedad. Se puede procesar al trasgresor del contrato, pero no a los terceros que se aprovechan de la información que éste ha puesto a su disposición. Ello no quiere decir que la acción de los free-riders no sea impugnable desde un punto de vista

73 Kinsella (2001). 
moral. No estamos haciendo aquí juicios morales, sino considerando qué es legítimo y qué no. Alguien perfectamente podría pensar que comprar una copia es un acto de menosprecio hacia el autor de la obra. Aquí únicamente nos interesa determinar si el individuo tiene o no derecho a proceder de esta manera.

Por último, puede que en algunas parcelas la protección por la vía contractual no sea, al menos tal y como la concebimos hoy, demasiado efectiva; en otras parcelas, en cambio, sí puede serlo. Sea como fuere hay otros mecanismos para excluir a los free-riders, como veremos a continuación, y quién sabe si los empresarios, que tienen fuertes incentivos para idearlos, encuentran nuevas fórmulas contractuales para proteger las creaciones.

\section{SOLUCIONES DE MERCADO}

¿Qué fórmulas podrían emplear los autores e inventores para rentabilizar sus creaciones en ausencia de monopolios legales? ¿De qué modo y en qué medida podrían protegerse de la competencia de los productos no-originales? El empresario es el primer interesado en excluir a los free-riders o usuarios no-compradores (los que copian el producto en lugar de comprarlo) si eso tiene que reportarle beneficios. Aplicará o intentará descubrir un método de exclusión eficaz tan pronto como advierta que puede aprovecharse de una oportunidad de ganancia latente. De esta manera se conciben espontáneamente en el mercado fórmulas que permiten recoger beneficios que de otro modo permanecerían sepultados. Surgen distintos mecanismos que nadie antes había imaginado para rentabilizar la producción de bienes deseados por los consumidores en los que puede incidir el fenómeno del free-riding.

A este respecto cabe matizar, no obstante, que la exclusión de free-riders no es siempre deseable ni necesaria para producir 
un determinado bien. De un lado, puede que el productor simplemente quiera que la gente se beneficie de un bien o servicio sin pagarlo ${ }^{74}$. Sería el caso del inventor que sólo quiere donar a la ciencia su descubrimiento, o del escritor que distribuye su obra por internet para darse a conocer y ganar popularidad y fama, o del ideólogo que radia sus ideas para que se extiendan todo lo posible, o de la cadena de televisión que intenta llegar al máximo de espectadores para aumentar sus ingresos por publicidad. No hay aquí ningún interés por parte del productor de excluir a los free-riders, antes al contrario. De otro lado, excluir a los no-compradores tiene un coste. Si en el mercado decide no excluirse a los no-compradores en determinados contextos no cabe atribuirlo tanto a la imposibilidad técnica de hacerlo como al coste que acarrea ${ }^{75}$. Nótese que prácticamente todos los empresarios-vendedores pagan costes de exclusión de una forma u otra: máquinas de refrescos selladas, guardias y cámaras de seguridad en las tiendas y supermercados, cristales en los aparadores de los comercios etc. son métodos de exclusión que se han ideado para excluir a los no-compradores del consumo del producto ${ }^{76}$. El hecho de que no todos los propietarios de tiendas pongan una cámara de seguridad, por ejemplo, se debe a que el dueño considera que el coste que supone su instalación y mantenimiento sobrepasa los ingresos que reporta (en forma de prevención del robo). Es decir, el dueño prefiere que algunos gamberros actúen como free-riders robando al año cuatro chucherías que tener que pagar por una cámara de seguridad. Excluir a los free-riders en este contexto no sería eficiente. Se arguye asimismo que los individuos

74 Benegas Lynch (1998).

75 «En otros términos, la mencionada no-internalización no constituye un defecto del mercado sino que, dadas las circunstancias imperantes, significa su optimización. Por tanto, la posición de las externalidades no-internalizadas es superior en cuanto a la eficiencia respecto de la internalización forzosa de aquellas externalides no deseadas». Íbid.

76 Holcombe (1997). 
tenderán a copiar en lugar de comprar, obviando que la propensión a aprovecharse de un bien sin pagarlo (convertirse en free-rider) no es la única que existe y no tiene por qué ser la más importante ${ }^{77}$. Los individuos, en atención a sus principios morales o sentido del deber, podrían considerar que respetar la autoría de un invento u obra es preferible a maximizar su renta monetaria. Confundir la maximización de la renta monetaria con la maximización del bienestar o la felicidad personal es olvidar que los individuos pueden extraer igualmente satisfacción de comportamientos ascéticos, morales o altruistas.

Antes de abordar las posibles fórmulas para rentabilizar invenciones que podrían surgir en ausencia de patentes y copyrights es preciso puntualizar que desde la teoría podemos analizar los procesos sociales pero no podemos desempeñar la función empresarial misma que tiene lugar en su seno y que es la que lleva a descubrir los mecanismos de exclusión de los nocompradores y otras soluciones de mercado. Estudiar y ejercer el papel del empresario son dos labores distintas, y el desarrollo de métodos de exclusión y fórmulas de rentabilizar inversiones no corresponde, en este sentido, al teórico de la economía sino al empresario. No obstante, sí podemos apuntar tentativamente fórmulas que se nos antojan factibles y que en buena medida están operativas en la actualidad, sin olvidar que no podemos juzgar la factibilidad de producir un bien sólo a la luz de las fórmulas actuales sino también, en razón de la naturaleza dinámica del mercado, a la luz de las que podrían surgir. Así, la siguiente enumeración de posibles soluciones de mercado no pretende en modo alguno ser exhaustiva.

- Arreglos contractuales: Con el objeto de hacer frente a los riesgos de invertir cuantiosos recursos en investigación y desarrollo y carecer del monopolio legal sobre la

\footnotetext{
77 Fielding (1979).
} 
explotación del invento, las empresas podrían extender contratos en los que se reconocieran mutuamente la exclusividad sobre un producto concreto durante un período determinado de tiempo. Como sugiere Gil Guillory, las compañías farmacéuticas, por ejemplo, podrían reconocerse mutuamente la exclusividad sobre explotación de un determinado producto durante $X$ años. El acuerdo resultaría eficaz en la medida en que fuera adoptado por un mayor número de empresas farmacéuticas ${ }^{78}$. Otro tipo de arreglos que podrían proliferar son los contratos de exclusividad: una empresa A cedería la comercialización exclusiva de su producto al vendedor B en una determinada área geográfica a condición de que $\mathrm{B}$ no distribuyera ninguna copia o genérico de su producto ${ }^{79}$. Los editores podrían establecer contratos de este tipo con librerías particulares o cadenas $^{80}$. A través de contratos con condicionantes, como hemos expuesto antes, es posible proteger directamente las obras y las invenciones, pero los contratos sólo vinculan a los compradores del original, no a terceros. Otra fórmula son los contratos unánimes: el productor reúne a los miembros del colectivo interesado en el bien y les indica que éste no se producirá a menos que cada uno se comprometa por contrato a pagar su parte alícuota siempre y cuando los demás hagan lo mismo ${ }^{81}$. Este arreglo contractual hace desaparecer todo incentivo a convertirse en free-rider, pues el potencial free-rider tiene la certeza de que no podrá consumir el bien sin pagarlo porque si no paga no hay posibilidad de que se produzca el bien ${ }^{82}$.

78 Gil Gillory, en Kinsella (2005).

79 Íbid.

80 Palmer (1989).

81 Friedman (1986).

82 Cuanto mayor sea el colectivo más difícil será, en principio, conseguir un acuerdo unánime, pero puede bastar con encontrar una «minoría privilegiada», 
- Secretos comerciales: En ausencia de propiedad intelectual pueden mantenerse igualmente secretos comerciales (no revelar a nadie los detalles de una particular invención). Coca-cola no ha patentado nunca su fórmula, y de haberlo hecho hubiera pasado al dominio público 17 años después del registro, en lugar de permanecer protegida durante décadas como secreto comercial ${ }^{83}$. La conclusión de múltiples estudios es que los empresarios valoran más los secretos comerciales que las patentes: alrededor del 51\% de los jefes de laboratorio y directores de empresas han sostenido que los secretos comerciales son efectivos para rentabilizar inversiones contra el $23-35 \%$ en el caso de las patentes $^{84}$.

- El primero en producir: Es preciso ponderar las ventajas derivadas de ser el primero en producir un bien. Por un lado, hay que tener en cuenta el valor publicitario y la lealtad del consumidor que resulta de ser el primero en sacar al mercado un producto popular ${ }^{85}$. Por otro lado, puede que duplicar con exactitud una invención determinada sea costoso y requiera mucho tiempo, lo cual da cierta ventaja al creador original. Asimismo cabe destacar la importancia de la curva de aprendizaje: si los costes de producción caen con el tiempo a medida que el productor

\footnotetext{
un subgrupo de ese colectivo que se beneficie lo suficiente de la producción del bien como para estar dispuesto a cargar él solo con el coste. Friedman (1986). De hecho los acuerdos no tienen por qué ser necesariamente unánimes dentro del grupo o subgrupo. Un individuo puede tener incentivos añadidos a contribuir si tiene la certeza de que también lo hará un número suficiente de individuos, de manera que su aportación no supondrá un despilfarro. Si cada consumidor potencial sabe que su contribución afectará el comportamiento de otros en el sentido de que contribuyan también, los incentivos a contribuir son mayores (pues si contribuyen la producción del bien está garantizada o es más probable). Palmer (1989).

83 Palmer (1989).

${ }^{84}$ Boldrin y Levine (2005).

85 Posner (2006).
} 
aprende más acerca de cómo manufacturar el bien a un coste menor, la empresa pionera tenderá a tener una ventaja relativa sobre los competidores que llegan después ${ }^{86}$.

- Discriminación de precios: Las empresas pueden practicar una discriminación temporal de precios, ofreciendo, por ejemplo, películas en DVD a un precio elevado en el momento de su estreno (para los entusiastas) y a un precio menor al cabo de unos meses. Actualmente también se discrimina en precios vendiendo ediciones de tapa dura de libros o ediciones especiales en DVD, precios diferenciados en revistas para particulares o para librerías, o precios rebajados para escolares, jubilados... en teatros, museos, cines... ${ }^{87}$

- Bienes y servicios añadidos: Otro mecanismo para rentabilizar la producción de bienes con problemas de freeriders consiste en atarlos a bienes de cuyo consumo puede excluirse más fácilmente a los no-compradores ${ }^{88}$. Los programas de software se atan a manuales, actualizaciones periódicas, servicio técnico... de modo que sólo los que compran los programas pueden beneficiarse de estos añadidos (los que copian los programas, los no-compradores, quedan excluidos de su disfrute) y el incentivo a convertirse en free-rider es menor ${ }^{89}$. Los programas de software también se atan a un «hardware» o a un sistema operativo concreto de forma que el programa no es compatible con los ordenadores o sistemas operativos de la competencia (uno puede copiar un programa de software pero para utilizarlo tiene que comprar el hardware o el sistema

86 Íbid.

87 Palmer (1989).

88 Cowen (1993).

89 Palmer (1989) La empresa McAfee Associates, por ejemplo, ofrece gratuitamente muchos de sus contenidos de seguridad para ordenadores a través de internet, obteniendo sus ingresos de las actualizaciones y de su servicio de atención al cliente. Shapiro y Varian (1999, p. 86). 
operativo de la empresa) $)^{90}$. Otro ejemplo es el de las guías de programación que se venden junto con las emisiones de las cadenas (el primero permite excluir a los freeriders $)^{91}$.

- Financiación de los fabricantes: Los primeros locutores de radio fueron financiados por los fabricantes de radio, que estimulaban de este modo la demanda de sus productos. Julio Cole sugiere que las industrias de hardware podrían hacer lo mismo con respecto al software: desarrollar software para estimular la demanda de sus productos hardware ${ }^{92}$.

- Publicidad: la mayoría de televisiones, radios, revistas y periódicos se financian básicamente a través de publicidad. En este contexto no supone un problema, antes al contrario, la ausencia de mecanismos para excluir a los no-compradores, pues no son ellos los que sufragan el bien o servicio. En un escenario sin propiedad intelectual la publicidad quizás jugara un papel más preponderante $e^{93}$.

- Codificación y sistemas anti-copia: La codificación de la señal de televisión sirve para excluir a aquellos que no abonan una cuota. Este tipo de mecanismos de exclusión podrían extenderse en el futuro (en el ámbito de internet, por ejemplo, en emisoras digitales o bancos de música). Los productos podrían incorporar también sistemas anticopia más sofisticados ${ }^{94}$.

- El boicot: Puede ser un instrumento útil para enfrentarse al problema de las copias indiscriminadas y el no-respeto de la autoría. Las empresas que exploten comercialmente

\footnotetext{
${ }^{90}$ Friedman (1986).

91 Palmer (1989).

92 Cole (2001).

93 Palmer (1989).

94 Íbid.
} 
las obras de otros autores sin su consentimiento, haciéndolo no obstante de forma legítima (sin violar ningún contrato), pueden ser condenadas al ostracismo por los consumidores. La historia nos muestra varios ejemplos exitosos de boicots de esta índole, por ejemplo el que organizó el Guild of Fashion Originators en los años 30 en Estados Unidos contra los estilos de moda plagiados por otros diseñadores ${ }^{95}$.

- Suscripciones y salarios: los escritores que buscan obtener ingresos directos de sus obras encontrarán modos de venderlas si existe una demanda ${ }^{96}$. Quizás haya un auge de las publicaciones con suscripción y se extienda el trabajo asalariado en el sector, así la remuneración de estos autores no dependería de la explotación de una obra sobre la que no se tienen garantías respecto a la exclusividad de su comercialización ${ }^{97}$.

- Actos en directo: los conciertos, las conferencias, los coloquios... podrían convertirse en una importante fuente de ingresos alternativa para cantantes y otros artistas y escritores académicos ${ }^{98}$.

- La copia como publicidad: La distribución masiva de copias vía directorios on-line de archivos musicales, por ejemplo, podría tener a veces incluso efectos promocionales. En abril de 2000 el álbum Kid $A$ de Radiohead se había filtrado a internet tres meses antes de su lanzamiento y cientos de miles de usuarios pudieron descargárselo a través de Napster. Cuando el CD de Kid $A$ salió a la venta se situó directamente en la primera

95 Íbid.

96 Algunos autores escriben en revistas científicas y journals académicos para acentuar su prestigio e incrementar así sus ingresos en otras actividades. Cole (2001).

97 Cole (2001).

98 Íbid. 
posición de la lista de éxitos estadounidense. Radiohead nunca había figurado siquiera en el top 20, por lo que hay quien sugiere que Napster pudo haber jugado un papel análogo al de las emisoras comerciales, que estimulan la demanda de álbumes radiando masivamente las canciones ${ }^{99}$.

Cabe señalar, por último, que el simple hecho de que bienes considerados públicos, como las emisiones televisivas o los programas de software, se produzcan en el mercado en cantidades tales que nadie alegará que están siendo subproducidos hace temblar todo el edificio teórico de los bienes públicos. Si la teoría establece que un bien público no se producirá en el mercado o se producirá en cantidades subóptimas (y se requiere la intervención del Estado) pero la realidad evidencia que un bien que se ajusta a la definición de bien público es producido privadamente en cantidades ingentes, o la teoría está viciada o la realidad «se equivoca». No puede argumentarse, por tanto, que los inventos o creaciones no se producirán en ausencia de intervención pública (en forma de propiedad intelectual) por el mero hecho de reunir las características que los definen como bien público, pues es palmario que existen bienes con esas características cuya producción se ha demostrado increíblemente rentable y nadie considera que escaseen ${ }^{100}$. Luego los que pretendan defender la propiedad intelectual parece que deben apelar necesariamente a algo más que al carácter de bien público de las ideas.

99 Menta (2000).

100 Holcombe (1997). 


\section{Patentes y compañías farmacéuticas}

El caso de los medicamentos se presenta frecuentemente como ilustrativo de la necesidad de las patentes, al menos en ciertos ámbitos, para que no se detenga la innovación. Sin los monopolios legales que permiten la explotación comercial exclusiva de un nuevo medicamento no podrían rentabilizarse las vastas inversiones en investigación y desarrollo que son necesarias para inventarlo. Las farmacéuticas, prosigue el argumento, no serían capaces de producir los medicamentos deseados por los consumidores si no se les garantizasen esas rentas monopolísticas prohibiendo las copias.

Sin embargo, si los medicamentos son bienes muy valorados por los consumidores significa que las oportunidades de ganancia latentes son extraordinarias, y los empresarios son los primeros interesados en encontrar fórmulas para aprovechar estas oportunidades de ganancia excluyendo a los no-compradores o por algún otro medio. De nuevo, desde la teoría no cabe ejercer la función empresarial que lleva a descubrir modos de rentabilizar inversiones, pues se trata de una labor eminentemente práctica que corresponde a los empresarios desempeñar. Como teóricos no cabe, por tanto, hacer predicción científica alguna con respecto a las fórmulas que pudieran extenderse en el ámbito de los medicamentos en un escenario sin patentes. Dicho esto, pasemos a explorar de qué modo parece que podría innovar la industria farmacéutica en ausencia de monopolios legales.

En primer lugar, en relación con las patentes habría que sopesar si el desincentivo a la creación que generan (en el período posterior al registro de la patente) y las limitaciones que imponen sobre el uso de los conocimientos existentes (patentados) no sobrepasan el incentivo a la innovación. Según declaró Peter Ringrose, jefe científico de la empresa farmacéutica Bristol-Myers Squibb, «la compañía no está trabajando en más de 50 
proteinas posiblemente relacionadas con el cáncer porque los titulares de las patentes no se lo permitirían o exigirian royalties excesivos» ${ }^{101}$. Sandy Weisburst y F.M. Scherer han estudiado la evolución de la industria farmacéutica en Italia antes y después de la introducción de las patentes y han concluido que durante la primera década desde la institución del régimen de patentes no se advirtió ningún aumento significativo de las innovaciones ${ }^{102}$. Por otro lado es preciso tener en cuenta el papel que juegan los secretos comerciales en este ámbito, así como las ventajas derivadas de ser la primera empresa en sacar al mercado un medicamento: valor publicitario y lealtad del consumidor, duplicación costosa del producto y curva de aprendizaje.

En el supuesto de que el fenómeno free-riding afecte gravemente a la industria quizás cabe considerar la posibilidad de que se llegue a producir por demanda en este sector y con respecto a ciertos productos. Puede que los consumidores paguen por anticipado una gama de medicamentos a un precio menor habiéndose aplicado un tipo de descuento, de manera que las farmacéuticas se asegurasen la rentabilización de los costes en $\mathrm{I}+\mathrm{D}$ o de una parte de éstos ${ }^{103}$. Es cierto que algunos consumidores estarán pagando por medicamentos que palian enfermedades que no tienen en ese momento, y que aquellos que tengan preferencias temporales más altas y prefieran gastar en el presente antes que invertir para el futuro no serán propensos a hacer este tipo de pagos por anticipado. Pero eso dependerá de las valoraciones subjetivas de cada individuo. Si ciertos medicamentos no llegan a producirse porque la gente decide destinar su dinero a la satisfacción de otros fines será que ex ante valora más destinarlo a esos fines que pagar para curar posibles enfermedades futuras.

101 Boldrin y Levine (2005).

102 Íbid.

103 Debo esta idea a Juan Ramón Rallo. 
Las farmacéuticas, como hemos señalado, también podrían firmar contratos de exclusividad por $\mathrm{X}$ años con las cadenas de distribución de modo que aquéllas cedieran el derecho de explotar en exclusiva sus productos en un área geográfica determinada a cambio de que las compañías de distribución no vendieran copias o genéricos de dichos productos. ¿Por qué esto no sucede hoy cuando las patentes prescriben? ¿Por qué tendrían que surgir entonces en un escenario sin patentes? Porque en un escenario sin patentes los incentivos serían distintos. En un escenario sin patentes si las cadenas de distribución no se plegaran a este tipo de arreglos contractuales quizás no se producirían medicamentos y no podrían comercializarlos. Por otro lado, las cadenas de distribución es posible que pagaran por anticipado para obtener esa exclusividad (algo parecido a lo que sucede en el mercado audiovisual con los derechos de antena: las televisiones compran un película antes de que se produzca para poder emitirla después, de modo que los productores rentabilizan así parte de su inversión).

Hay que tener en cuenta, asimismo, los costes inherentes a los controles sanitarios y de calidad impuestos por organismos públicos como la Food and Drug Administration (FDA) de Estados Unidos. Para el período 1990-1996 la comercialización de un medicamento tardaba de media casi nueve años en aprobarse, entre pruebas clínicas y otros requisitos ${ }^{104}$. Los dilatados costes de este proceso se reducirían si se aboliera la FDA. La libertad de elección de los consumidores y los certificados privados de calidad (que ya están hoy bastante generalizados) ocuparían su lugar. Los organismos como la FDA no sólo son completamente prescindibles, sino que son sumamente lesivos. Los estudios indican que los perjuicios de retardar la comercialización de medicamentos efectivos (a causa de las regulaciones de la FDA) exceden con creces los beneficios derivados

104 Tabarrok (2000). 
de unas mejores garantías en ciertos $\operatorname{casos}^{105}$. Suprimir la FDA y sus homólogos en los demás países no sólo beneficiaría a los consumidores, también eximiría a las farmacéuticas de una farragosa carga que dificulta artificialmente la rentabilización de sus inversiones.

Por último, es preciso tener en cuenta que las farmacias retienen el monopolio legal sobre la venta de medicamentos. En un mercado liberalizado los medicamentos podrían venderse, por ejemplo, en supermercados, y la competencia entre los distintos puntos de venta probablemente resultara en ofertas más atractivas para los consumidores.

\section{MARCAS Y FRAUDE}

Copiar marcas para engañar a los consumidores es ilegítimo no porque las empresas tengan un derecho de propiedad exclusivo sobre su marca particular, sino porque supone un fraude al consumidor ${ }^{106}$. Coca-cola o Danone no detentan ningún derecho de propiedad sobre sus respectivas marcas, del mismo modo que nosotros no tenemos derecho de propiedad alguno sobre nuestros nombres. Si alguien decide llamarse igual que nosotros no alegaremos que está invadiendo una propiedad que nos pertenece (el nombre), luego si una empresa copia una marca tampoco puede ser acusada de infringir un derecho de la empresa original. Pero sí puede ser acusada de cometer fraude al consumidor si su propósito es engañarle.

En la transferencia de títulos de propiedad por la vía contractual tienen una importancia fundamental los condicionantes

105 Se estima que de comercializarse antes los medicamentos en lugar de esperar a la aprobación de la FDA se hubiera evitado la muerte de centenares de miles de personas en Estados Unidos. Las personas que, en cambio, han salvado su vida debido a las mayores garantías del medicamento tras recibir el visto bueno de la FDA se cuentan por miles. Íbid.

106 Kinsella (2001). Para una réplica a las tesis de Kinsella sobre las marcas véase Dun (2003). Para un réplica a las objeciones de Dun véase Kinsella (2004). 
implícitos. Está claro que si traspasamos una cantidad de dinero a cambio de una manzana y nos dan una naranja alegaremos fraude porque nosotros hemos transferido nuestro dinero a condición de que nos den una manzana. Pero no es menos cierto que implícitamente se entiende que estamos solicitando una manzana en buen estado, no una manzana podrida o que esté envenenada. No es preciso que en cada transacción hagamos explícitos aquellos condicionantes que las partes ya asumen por convención. Cuando compramos un coche no hace falta explicitar que lo queremos con motor, las partes obviamente entienden que el motor va incluido cuando se demanda un coche. Trasladando esta idea al ámbito de las marcas, cuando compramos a una empresa que ha copiado la marca de una tercera se está cometiendo un fraude si creemos que estamos comprando a la empresa original, pues al comprar lo hacemos con la condición implícita de que se trata de la empresa original. Aquella empresa que se sirve de la reputación de una marca establecida para acaparar consumidores que creen razonablemente estar comprando en la empresa original (que es la que tiene para ellos esa reputación, esa solvencia, esa imagen determinada) está defraudando a estos consumidores ${ }^{107}$. No está violando ningún derecho de propiedad de la empresa original, sino que está engañando a sus compradores haciéndose pasar por aquélla. Cuando los consumidores se dirigen a una marca concreta que conocen y a la que asocian una serie de cualidades (más abstractas o más concretas), en efecto asumen que se trata de la empresa original y no de una empresa que ha copiado la marca, por lo que en este segundo caso no se estaría cumpliendo el condicionante implícito de que se trate de la empresa original. Imaginemos que una recién creada

107 Es importante señalar que la comisión de un fraude no depende enteramente de la percepción del consumidor. La expectativa del consumidor debe estar fundamentada, de modo que tenga razones suficientes para alegar que ha sido en efecto engañado / defraudado. 
empresa de yogures se hace llamar Danone y utiliza su mismo logo arguyendo que la Danone original no tiene ningún derecho de propiedad sobre ese nombre. De esta manera se lucraría aprovechándose de la reputación que Danone ha acumulado durante décadas. Pero si compramos un yogur de la marca Danone no estamos pidiendo sólo un yogur que lleve impreso las letras Danone, sino un yogur que no sea venenoso, que no esté caducado etc... y un yogur que sea de la marca Danone original, a la cual asociamos determinadas cualidades. La gente compra el yogur de la nueva Danone por lo que asocia a la Danone original, es decir, asumiendo que es la Danone original con todo lo que esa marca conlleva. Por tanto, de la misma manera que alegaremos fraude si nos venden un coche sin motor o una manzana podrida, alegaremos fraude si una empresa copiara una marca para vendernos productos aparentando ser la empresa original.

Los consumidores están siendo defraudados si compran un bien a condición de que sea de la empresa original y en realidad es de una empresa con la marca copiada. No obstante, si compran sabiendo que no se trata de la empresa original no tiene lugar fraude alguno. El consumidor no pone en este caso la condición, ni explícita ni implícita, de que tiene que tratarse de la empresa original. Es plenamente consciente de que está comprando a la empresa que copia la marca. Si compramos un polo Lacoste copiado por un tercio del precio del original sabiendo que, en efecto, se trata de una copia, no se está cometiendo fraude alguno. La empresa original sigue vendiendo sus polos a los consumidores que quieren comprar a la empresa original, mientras que la empresa con la marca copiada vende a los que quieren (porque son más baratos o lo que fuera) comprar polos copiados. Mientras la empresa que copia no se haga pasar por la empresa original, engañando así al consumidor, todos obtienen lo que buscan y nadie está siendo defraudado. 
El caso de que alguien firme su libro con el nombre de un autor famoso para así disparar sus ventas es análogo al caso de las marcas. El nombre de un autor famoso es como el de una marca. Si los consumidores compran un libro creyendo razonablemente que ha sido escrito por ese autor famoso pero en realidad no es así, están siendo víctimas de un fraude. Pero, ¿qué sucede si alguien firma con el nombre de otro autor que no es famoso? ¿Acaso no podemos firmar con pseudónimos o con nombres falsos? En tanto el consumidor no esté asumiendo como condición implícita que el libro está escrito por ese autor concreto, no se comete fraude. Si compramos un libro por su contenido, sin fijarnos en absoluto en el nombre del autor, no estamos poniendo como condición implícita de la transferencia que se trate de este autor o aquel otro. Si vamos a comprar un libro de Michael Crichton queremos que esté escrito por Michael Crichton, y en caso de que lo haya escrito Pepe Martínez y éste haya firmado con el nombre de Michael Crichton estaremos siendo víctima de un fraude. Pero si alguien firma con el nombre de un autor desconocido (o con un pseudónimo o nombre falso) de modo que nosotros no compramos el libro por su autor sino porque nos atrae el contenido o lo que fuera, no estamos contemplando la autoría como un condicionante implícito. El autor que ha puesto el nombre de otro no se está aquí sirviendo de la reputación de un tercero para engañarnos. Nosotros ni siquiera sabemos de la existencia de aquél. Por otro lado, ¿qué incentivos tiene el autor de este libro para firmar con el nombre de un autor desconocido si no va a poder aprovecharse de su fama ni de su prestigio? El autor tiene incentivos para poner el nombre de Michael Crichton y aumentar así sus ventas (lo cual constituye un fraude), pero no tiene incentivo alguno para poner el nombre de un autor desconocido en lugar de, por ejemplo, un pseudónimo. No extrae ningún beneficio de firmar con el nombre de un autor desconocido que no extraiga de firmar con pseudónimo o nombre falso, 
motivo por el cual no hay razones para pensar que esta práctica vaya a generalizarse en absoluto.

Podría replicarse que sí que se produce un fraude siempre que se firma con el nombre de otro porque el consumidor siempre asume que el libro que está comprando está escrito por el que firma. Pero es dudoso que esto sea realmente así cuando a menudo compramos libros sin apenas reparar en quién los firma, lo cual puede considerarse sintomático de que en muchos casos no nos importa.

\section{SECRETOS COMERCIALES}

Un secreto comercial consiste en una información confidencial sobre una fórmula, un proceso, un modelo, un método, una compilación de datos etc. que confiere a su tenedor una ventaja competitiva en tanto permanezca secreta. Los secretos comerciales son utilizados para prevenir apropiaciones indebidas o exigir reparaciones por estas apropiaciones indebidas. En este sentido la ley en materia de secretos comerciales o empresariales no comporta ningún derecho de propiedad sobre ideas (sobre la información contenida en el secreto comercial) mientras se aplique contra personas que obtienen la información de manera ilegítima o contraviniendo sus obligaciones contractuales $^{108}$. Si un empleado de la empresa $X$ revela al competidor $\mathrm{Z}$ un secreto comercial que contractualmente está obligado a no revelar incurre en una violación de contrato punible. La empresa competidora $Z$, sin embargo, no está sujeta a ningún contrato con la empresa $X$, y si no tiene ninguna relación con el empleado tránsfuga puede disponer libremente de la información recibida ${ }^{109}$. No obstante sucede con frecuencia

108 Kinsella (2001).

109 Más arriba hemos discutido sobre la protección contractual y como ésta sólo vincula a las partes. 
que el competidor $Z$ puede ser acusado de conspirar o actuar en connivencia con el empleado tránsfuga si ambiciona el secreto comercial y sabe de la existencia de dicho empleado. Si el empleado no viola su contrato hasta que revela el secreto y la empresa competidora $Z$ le insta activamente a hacerlo, entonces $Z$ está siendo cómplice de la violación de contrato del empleado. El caso de la empresa competidora es análogo al del capo de la mafia que ordena un asesinato o al conductor del coche que los ladrones utilizan para huir de un robo. Tanto el capo como el conductor participan del delito aun cuando no han sido ellos los autores materiales del asesinato o del robo. En este supuesto la empresa competidora también participaría de la violación de contrato aunque fuera el empleado el que la llevara a cabo ${ }^{110}$.

\section{CONCLUSIONES}

En el presente trabajo hemos intentado demostrar que la propiedad intelectual no está justificada desde un punto de vista ético y que su coartada utilitarista es, en realidad, menos convincente de lo que parece. Desde una perspectiva ética se ha argumentado que las patentes y los copyrights confieren derechos de control parciales sobre la propiedad tangible de terceros, lo que atenta contra el derecho de propiedad de los poseedores naturales. Por otro lado, la propiedad emana de la escasez y las ideas no son bienes escasos. No es posible que haya conflicto con respecto a los usos alternativos de una idea porque éstos no son excluyentes, luego las ideas no pueden ser objeto de apropiación. Tampoco tiene sentido reclamar un derecho de propiedad sobre una idea que ya está en la mente de otros, pues sólo cabe ejercer tal derecho sobre aquello que podemos

110 Kinsella (2001). 
en efecto controlar. Además, la distinción entre descubrimientos no patentables e inventos patentables y los límites temporales de las patentes y los copyrights son por entero arbitrarios. Desde una perspectiva económica-utilitarista hemos disputado que el progreso motivado por la propiedad intelectual sea tan ostensible como alegan sus valedores, y al mismo tiempo hemos señalado los ingentes costes que este tipo de regulaciones conllevan. Hemos apuntado también la posibilidad de proteger las obras artísticas y los inventos mediante contratos, distinguiéndolos de los copyrights y sus derechos reservados, que vinculan a todos y no únicamente a las partes que consienten. Asimismo se han sugerido algunas alternativas de mercado a las patentes y a los copyrights y se ha examinado en particular el ámbito de los medicamentos, que pese a constituir el ejemplo más fuerte en pro de las patentes no ha modificado nuestras conclusiones. Por último hemos defendido la legitimidad de las marcas en función, no de la propiedad intelectual, sino del fraude que supone copiarlas para engañar al consumidor, así como la legitimidad de los secretos comerciales, que protegen información valiosa de las apropiaciones indebidas.

\section{REFERENCIAS BIBLIOGRÁFICAS}

BelL, Tom (2002), «Copy Fighting», Tech Central Station. http: / / www.tcsdaily.com/article.aspx?id=080502B, $8 / 5 / 2002$.

Benegas Lynch, Alberto (1998), «Bienes públicos, externalidades y los free-riders: el argumento reconsiderado», Estudios Públicos, Chile, 71.

BoldRIN, Michael, y LeVINE, David (2005), «Against Intellectual Monopoly», borrador on-line: http:/ / levine.sscnet.ucla.edu/general/intellectual / against.htm, 11/11/2005. 
BROwnE, Harry (1997), «Andrew Galambos. The Unkown Libertarian», Liberty, noviembre.

Cole, Julio H. (2001), «Patents and Copyrights: Do the Benefits Exceed the Costs?», Journal of Libertarian Studies, 15 (4), pp. 79-105.

- (2003) «Propiedad Intelectual: Comentarios Sobre Algunas Tendencias Recientes», Revista Empresa y Humanismo, Universidad de Navarra, 6, pp. 35-48.

Cowen, Tyler (1993), «Public goods and externalities», Concise Encyclopedia of Economics, David R. Henderson (ed.).

Dun, Frank van (2003), «Against Libertarian Legalism: A Comment on Kinsella and Block», Journal of Libertarian Studies, 17 (3), pp. 63-90.

Esplugas Albert (2006), «Bienes públicos: fallo del mercado o coartada del Estado», Liberalismo.org, http://liberalismo.org/articulo/364/

Evers, Williamson M. (1977), «Toward a Reformulation of the Law of Contracts», Journal of Libertarian Studies, 1 (1), pp. 3-13.

Fielding, Karl T. (1979) «Nonexcludability and Government Financing of Public Goods», Journal of Libertarian Studies, 3 (3), pp. 293-298.

Friedman, David (1986), «Price Theory: An Intermediate Text», Cincinnati, South-Western Publishing.

Holcombe, Randall G. (1997), "A Theory of the Theory of Public Goods», Review of Austrian Economics, 10 (1), pp. 1-22.

Hoppe, Hans-Hermann (1989), «A Theory of Socialism and Capitalism: economics, politics and ethics», Boston, Kluwer Academic Publishers.

Huerta De Soto, Jesús (2004), «La teoría de la eficiencia dinámica», Procesos de Mercado: Revista Europea de Economía Política, vol. I, n. ${ }^{\circ}$ 1, pp. 11-71.

KInSELla, Stephan (2001), «Against Intellectual Property», Journal of Libertarian Studies, 15 (2), pp. 1-53. 
- (2003), «A Libertarian Theory of Contract: Title Transfer, Binding Promises and Inalienability», Journal of Libertarian Studies, 17 (2), pp. 11-37.

- (2004), «Reply to Van Dun: Non-Agression and TitleTransfer», Journal of Libertarian Studies, 18 (2), pp. 55-64.

- (2005), «There is no such thing as a free patent», Mises Daily Article, http: / / www.mises.org/fullstory.aspx?Id=1763, 7/3/2005. KIRZNER, Israel (1989), «Creatividad, capitalismo y justicia distributiva», Madrid, Unión Editorial [1995]

KRILL, Paul (2005), «Red Hat exec criticises software patents, Microsoft», Computerworld, 22/4/2005.

LAndes, William y Posner, Richard (2003), «The Economic Structure of Intellectual Property Law», Cambridge, The Belknap Press of Harvard University Press.

LoNG, Roderick T. (1995), «The Libertarian Case Against Intellectual Property Rights», Formulations, 3, 1.

MentA, Richard (2000), «Did Napster Take Radiohead's New Album to Number 1?», MP3newswire.net, http:/ / www.mp3newswire.net/stories/2000/radiohead. html, 28/10/2000.

PAlmer, Tom (1989), «Intellectual Property: A Non-Posnerian Law and Economics Approach», Hamline Law Review, 12, 1. - (1990) «Are patents and copyrights morally justified? The Philosophy of Property Rights and Ideal Objects», Harvard Journal of Law \& Public Policy, 13, 3.

Posner, Richard (2006), «Pharmaceutical Patents», The BeckerPosner Blog, http:/ / www.becker-posner-blog.com/archives/2004/12/pharmaceutical_1.html, 12/12/2006.

RothBARD, Murray (1956), «Toward a Reconstruction of Utility and Welfare Economics», Auburn, The Mises Institute [2002].

- (1962), «Man, Economy and State», Auburn, The Mises Institute [2004]. 
- (1973), «For a New Liberty», Auburn, The Mises Institute [2002].

- (1982), «La ética de la libertad», Madrid, Unión Editorial [1995].

Shapiro, Carl y VArian, Hal (1999), «El dominio de la información», Barcelona, Antoni Bosh (ed.).

SPOONER, Lysander (1855), «The Law of Intellectual Property: or an Essay on the Right of Authors and Inventors to a Perpetual Property in Their Ideas», en The Collected Works of Lysander Spooner, Vol. 3, Charles Shively (ed.).

TABARROK, Alexander T. (2000), "Assessing the FDA via the Anomaly of Off-Label Drug Prescribing», The Independent Review, 5 (1), pp. 25-53.

Texto Refundido de la Ley de Propiedad Intelectual, Real Decreto Legislativo 1/1996, de 12 de abril.

Ley de la Propiedad Intelectual, Real Decreto Legislativo 1/1996 de 12 de abril.

Ley de Patentes de Invención y Modelos de Utilidad 11/1986 de 20 de marzo.

United States Constitution, 1789. 